
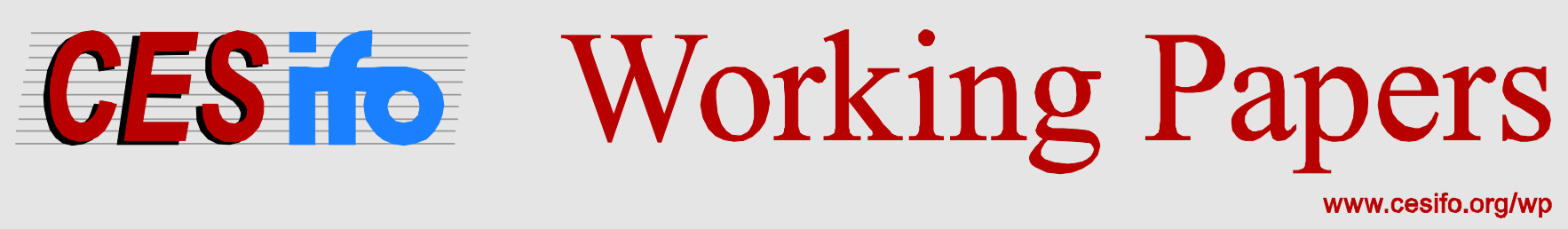

\title{
Family-Specific Investments and Divorce: A Theory of Dynamically Inconsistent Household Behavior
}

\author{
Dan Anderberg \\ Helmut Rainer \\ Kerstin Roeder
}

CESIFO WORKING PAPER NO. 5996

CATEGORY 13: BEHAVIOURAL ECONOMICS JULY 2016

An electronic version of the paper may be downloaded

- from the SSRN website:

- from the RePEc website:

wWw.SSRN.com

www.RePEc.org

- from the CESifo website:

www.CESifo-group.org/wp 


\title{
Family-Specific Investments and Divorce: A Theory of Dynamically Inconsistent Household Behavior
}

\begin{abstract}
This paper bridges two distinct areas of inquiry: the economic theory of the family and behavioral research on time-inconsistent preferences. In our model, hyperbolic discounting couples engage in household production activities, thereby accumulating family-specific capital over time. At any given point in time, the gains to continued marriage depend on the accumulated stock of this capital and a temporary random shock to match quality. Couples whose match quality deteriorates may choose to divorce, and this is more likely to happen if past investments in family-specific capital have been low. We obtain three main sets of results. First, present-biased preferences induce couples to underinvest in family-specific capital and to "overdivorce". Second, sophisticated couples - but not naive ones - may choose to enter marriage on terms which make divorce more costly to obtain. Third, the inefficiencies in the behavior of time-inconsistent couples can be completely undone by means of earnings and divorce taxes that vary over the marital life-cycle. In calibrating the model to the US economy, we demonstrate that the efficiency-restoring earnings tax is genderneutral and fairly flat with respect to marriage duration. The optimal divorce tax is an inverted- $U$ function of marriage duration, reaches its maximum when children are in their teens, and declines thereafter. We use our results to interpret several stylized facts about marriage and divorce that cannot be straightforwardly reconciled with standard models of household behavior. Examples include: marriage contracts that serve as barriers to hasty divorces (e.g., "covenant" marriages, the Islamic "mehr" or the Jewish "ketubah”); couples' overoptimism regarding the survival chances of their own marriage, despite knowing the statistics on divorce; and frequent regrets among divorced couples about their separation.
\end{abstract}

JEL-Codes: D030, D100, J120, H210.

Dan Anderberg

Royal Holloway

University of London / UK

dan.anderberg@rhul.ac.uk

\author{
Helmut Rainer \\ Ifo Institute - Leibniz Institute for \\ Economic Research \\ at the University of Munich / Germany \\ rainer@ifo.de
}

\author{
Kerstin Roeder \\ University of Augsburg / Germany \\ kerstin.roeder@wiwi.uni-augsburg.de
}


"Of course there are cases where divorce is inevitable. I haven't sat in the courts for 40 years without knowing that there are cases where it is just as well the parties separated. But it has been obvious to me that, by and large, a significant proportion of people who separate wish they had not five years down the line."

- Sir Paul Coleridge (Former High Court Judge, 9 February 2016)

\section{Introduction}

With Gary Becker's path-breaking Treatise on the Family, scholars started to use economic theory to describe a broad variety of intrahousehold decision problems. A common thread in the literature that has developed since then is the argument that the basic dynamics of family life can be explained within a framework in which family members behave fully rationally over time. Put differently, it has been routinely assumed that decisions about marriage and divorce, household production, labor supply, childbearing and childrearing are made by perfectly foresighted and timeconsistent partners.

In a parallel but unrelated development, the last decades have also witnessed the emergence of behavioral research in economics showing that instant gratification overpowers long-term considerations when individuals make decisions in a dynamic setting. Economists have coined the notion of time inconsistency to describe this phenomenon. Individuals with time-inconsistent preferences discount the future hyperbolically rather than exponentially and therefore make their decisions with a present bias. Thus, they are unable to consistently follow a utility-maximizing plan over their lifetime. Today it is well understood how time-inconsistent preferences affect consumption decisions, saving for retirement or health behavior, and the policy implications that come with it have received considerable attention.

Our paper argues that it is important to also entertain the possibility that family decisions are made with a present bias. This is underscored by several phenomena that cannot be easily reconciled with standard models. First, social scientists and practitioners have long emphasized that a substantial fraction of divorced people express regrets about their choice to separate, even many years later (e.g., Waite et al., 2002). In particular, many divorcees appear to regret the way in which the split affected their children or wish they had avoided the financial consequences. Second, there is abundant evidence that couples are overly optimistic regarding the survival chances of their own marriage, despite correctly assessing the likelihood of divorce in the population at large (e.g., Baker and Emery, 1993). Third, in various cultures and religions around the world, it is common to observe marriage contracts that include clauses preventing unrestricted divorces (e.g., the Islamic "mehr", the Jewish "ketubah", or "covenant" marriages). As of yet, mainstream family economics has not dealt in any systematic way with the possibility that such contracts - by making it 
difficult to obtain a divorce - may offer a useful commitment device for couples. This seems important not least because much of the western world has recently seen a development in the opposite direction: the introduction of no-fault divorce substantially facilitated obtaining a divorce.

One of our contributions is to show how one can systematically think about these issues by looking at family decisions through the lens of a model of dynamically inconsistent household behavior. Moreover, we argue that this perspective has interesting and strong policy implications, be it in the area of income taxation of couples or regarding policies regulating marriage and divorce.

At a general level, we envisage a setting in which hyperbolic-discounting couples engage in household production activities, thereby accumulating family-specific capital over time. The example of family-specific capital we have in mind are children, and so our notion of household production centers around the repeated choice how to allocate time between parental investments in children and working in the labour market. Couples are periodically exposed to a shock to match quality. Couples whose match quality deteriorates may choose to divorce, and this is more likely to happen if past investments in family-specific capital have been low. We view children as pure household public goods when parents are married. However, once a couple divorce, their children become an impure public good in that one or both parents will no longer be able to fully enjoy the value of the time investments. Married spouses make their resource allocation choices cooperatively whereas once divorced they act non-cooperatively. Eventually the children leave the parental home and the couple's investments in family-specific capital cease.

We first formalize these ideas in a stylized three-period model - the simplest setting necessary to study hyperbolic-discounting individuals. In the first period, married couples decide how to allocate their time between household production and working in the labor market. At the beginning of the second period, each couple is exposed to a match quality shock and decide whether to continue marriage or to divorce. They then once again allocate their time between labor market activities and home production. In the third period, no household production takes place, but individuals still benefit from the stock of previously accumulated family-specific capital. In this setting, we compare the laissez-faire allocation with the first-best choices. In characterizing the first-best, we follow O'Donoghue and Rabin (2006) and treat individuals' preference for short-term gratification as an error.

Several important insights follow from this comparison; here we mention three. First, a present-biased couple terminate their marriage for a larger set of match quality realizations than would be optimal (i.e., they "overdivorce"). Why is that the case? Present-biasedness implies that they overreact to negative temporary match quality shocks as they place too little weight on the value of continued marriage in terms of its positive impact on future investments in and enjoyment of family-specific capital. Second, time-inconsistent preferences induce a procrastination problem in which couples ex-ante underinvest in family-specific capital, a result that holds for both sophisticated and naive couples. Third, sophisticated married couples on the one 
hand recognize their tendency to over-divorce in the future and that this distortion can be mitigated by increasing their current investments; this gives them a strategic investment incentive. Naive married couples on the other hand hold overly optimistic beliefs about their future marriage survival chances and hence also about their future enjoyment of any current investments; this over-optimism bias mitigates their underinvestment. Indeed, naive couples will typically, if anything, invest more than sophisticated ones, a result contrary to conventional wisdom that naifs procrastinate more than sophisticates (O'Donoghue and Rabin, 1999a).

We further show that sophisticated couples - but not naive ones - would like to have a commitment device preventing them from obtaining a divorce "too easily". Various cultures and religions around the world do offer versions of such commitment devices. In the US, the so-called "covenant" marriage has been a legally distinct kind of marriage in Louisiana, Arkansas and Arizona since the 1990s. The marrying spouses agree to sign a statement declaring that a covenant marriage is for life. They voluntarily choose to limit the grounds for divorce to adultery, felony and abuse (Spaht, 1998). If one of the spouses desires a divorce, the couple is first required to attend marital counseling. Thus, divorce becomes a costly option. Muslim marriages also feature a commitment device in the form of the so-called "mehr". A mehr is composed of two parts: the "muqaddam" which is paid by the groom upon marriage to honor his bride, and the deferred "mu'akhkhar" component which is paid to the woman in the event of divorce (Blenkhorn, 2002). The latter makes divorce an expensive endeavor for husbands in particular. A very similar role is played the so-called "ketubah" in the Jewish religion (Hardin, 1988). While standard models of family decision-making have difficulties in rationalizing why these devices exist, we show that sophisticated couples may have an incentive to ex-ante opt for such contracts. In addition, we establish that this incentive is particularly pronounced in environments in which divorce rate is naturally low.

The final question we address is: what interventions are necessary to implement the first-best choices? We show that a suitably designed policy can completely undo the inefficiencies in the behavior of time-inconsistent couples by means of earnings and divorce taxes that vary over the marital life-cycle. In our setting, the earnings tax implicitly subsidizes household production; in each period, it corrects for the share of the future returns of family-specific investments not internalized by presentbiased couples. The divorce tax corrects for the fact that couples overreact to negative match-quality shocks.

In order to fully understand the properties of the efficiency-restoring policy scheme, we extend our three-period model to a more general $T$-period setup and calibrate this model to the US economy. This exercise reveals that even a modest degree of present-bias has a quantitatively important impact on divorce hazards. The efficiencyrestoring divorce tax is an inverted- $U$ function of marriage duration, reaches its maximum when children are in their teens, and declines thereafter. The effect of present bias on investments in family-specific capital turns out to be quantitatively 
smaller than its impact of divorce decisions, and the efficiency-restoring earnings tax is relatively flat with respect to marriage duration.

We proceed as follows. Section 2 relates our analysis to previous studies in several fields. Section 3 presents our stylized three-period model. Section 4 analyzes sophisticated couples' family-specific investments and divorce decisions over time. Section 5 characterizes the first-best allocation and describes the inefficiencies arising due to present bias. Section 6 characterizes privately optimal marriage contracts. How the first-best allocation can be decentralized through policy is described in Section 7. Section 8 comments on the behavior of naive couples. Section 9 extends the three-period model to a fully-dynamic setting and presents results from a calibration exercise. Section 10 contains concluding remarks.

\section{Related Literature}

We see our main contribution in connecting the economic theory of the family with behavioral research on time-inconsistent preferences. A recurring theme in the family economics literature is the idea that greater investment in family-specific capital tends to increase the incentives of couples to stay in a marriage. This idea has been formalized using various approaches. The earlier literature has build tractable models which assume household decisions to be Pareto efficient (Becker, 1973, 1974; Becker et al. 1977; Weiss and Willis, 1985, 1997; Clark, 1999). A more recent literature emphasizes the possibility that household behavior is inefficient, either because marriage-specific investments cannot be contracted upon or because couples behave non-cooperatively (e.g., Lommerud, 1989; Konrad, 1995; Konrad and Lommerud, 2000; Lundberg and Pollak, 2003; Rasul, 2006; Mazzocco, 2007; Rainer, 2007; Barham et al., 2009). While our framework retains a number of features in common with these models, we suggest a behavioral view of family decision-making which emphasizes the implications of dynamic inconsistency.

In so doing, we build on an impressive body of research analyzing hyperbolic discounting and its implications for consumption decisions (e.g., Laibson, 1997; 1998; Angeletos et al., 2001; Thaler and Benartzi, 2004; Meier and Sprenger, 2010), saving for retirement (Diamond and Köszegi, 2003) and health behavior (e.g., Byrne and Thompson, 2001; Gruber and Köszegi, 2004; and Ikeda et al. 2010). The key results in these studies are that hyperbolic discounting agents save too little and underinvest in screening and disease prevention. From a policy perspective, a lot of thought has gone into understanding the implications of time-inconsistent preferences for social security schemes (İmrohoroğlu et al., 2003; Schwarz and Sheshinski, 2007), the optimal design of sin taxes (O'Donoghue and Rabin, 2003, 2006; Gruber and Köszegi, 2004), or uniform saving floors (Malin, 2008).

Our paper also makes contact with two other strands of literature. The first concentrates on the question of whether age-dependent taxes can be Pareto-improving (e.g., Blomquist and Micheletto, 2008; Weinzierl, 2011; Bastani et al., 2013). Our 
paper brings two new dimensions to this literature: behavioral issues related to present-bias and taxes that vary over the marital life-cycle. The second literature strand deals with the optimal income taxation of couples and is mainly concerned with the design of gender-specific tax schedules (e.g., Boskin and Sheshinski, 1983; Alesina et al., 2011; Immervoll et al., 2011; Meier and Rainer, 2015). A conventional result that emerges from these studies is that the spouse with the higher labor supply elasticity - typically the female spouse - should be taxed at a lower rate. Our results suggest that, with time-inconsistent couples, there will be additional drivers in the design of optimal income tax schedules that call for gender-neutral taxes, even if spouses differ in their labor supply elasticities.

\section{A Stylized Three-Period Model}

We consider a three-period model with time indexed by $t=1,2,3$. The economy is populated by men and women, and at the outset of the model, at $t=1$, each individual is exogenously matched with a partner of opposite sex. Later on, at $t=2$, a given couple may divorce and we then let $k=m, d$ indicate marital status. In every period, men and women are endowed with one unit of time which they can allocate between household production and labor market activity. Time spent in household production allows the couple to build up their family-specific capital. The example we have in mind is children, and so our notion of household production centers around parental time investments in their children.

\subsection{Payoffs}

Marriage. The utility of a married individual $i$ in period $t$ is given by

$$
u_{i t}^{m}=x_{i t}^{m}+G_{t}^{m},
$$

where $x_{i t}^{m}$ is the individual's private consumption and $G_{t}^{m}$ is the accumulated family capital good. We index the partners by $i=s, h$ (for "she" and "he" respectively). In the second period, the couple are further exposed to a match quality shock, denoted $\theta$, which enters additively if they stay married. For simplicity we assume that both partners perceive the match quality shock in the same way. The shock is assumed to be temporary: it affects the payoffs in the second period but does not persist into 
the third period. ${ }^{1}$ An adverse match quality shock may, as outlined below, trigger a divorce.

Divorce. A divorced individual's utility in period $t$ is given by

$$
u_{i t}^{d}=x_{i t}^{d}+\lambda_{i} G_{t}^{d}
$$

Thus, the payoffs of divorcees differ from those of their married counterparts in two ways. First, the match quality shock $\theta$ becomes irrelevant. Second, partner $i$ may no longer enjoy the family capital good at a rate of unity but rather at a rate $\lambda_{i} \in[0,1]$. For notational convenience, we define $\Lambda \equiv \lambda_{s}+\lambda_{h}$ and assume that at least one of the two partners enjoys the family capital good at a lower rate after divorce, $\Lambda<2 .^{2}$

Intertemporal Preferences Following Laibson (1997), individuals' intertemporal preferences are characterized by (quasi-)hyperbolic discounting also known as $(\beta, \delta)$ preferences. The advantage of this preference structure is that it nests the standard (exponential) discounting model as a special case. An individual's intertemporal preferences at time $t$ are represented by

$$
V_{i t}=u_{i t}+\beta \sum_{\tau=t+1}^{3} \delta^{\tau-1} u_{i \tau}
$$

where $\delta \in[0,1]$ represents long-run time-consistent discounting, while $\beta \in[0,1]$ is a bias for the present (O'Donoghue and Rabin, 1999b). The latter reflects whether the individual is an exponential discounter $(\beta=1)$ or a hyperbolic discounter $(\beta<1)$. Hyperbolic discounters have a higher discount rate over short horizons than over long horizons. Hence, there exists a conflict between current preferences and those in the future. In particular, for $\beta \in(0,1)$ the discount factor between the second and third period is $\beta \delta$ when viewed from the second period, while it is $\delta$ when viewed from the first period. Thus, preferences are time inconsistent, and individuals face a self-control problem. Individuals can be either sophisticated or naive. The former foresee their time inconsistency and undertake steps to manage it while the latter do not perceive their self-control problem and wrongly expect themselves to behave time consistently

1. The assumption that the partners perceive the match quality shock the same way could be relaxed to allow for individual shocks. A couple's divorce decision would then be based on the sum of the individual match quality shocks. The assumption that the match quality shock is transitory can also be relaxed to allow it to persist into the final period. However, the assumption of a pure transitory shock makes the results from the three period model directly comparable to the full dynamic model in Section 9 where it is assumed that a couple experience a temporary shock in every period.

2. This captures the idea that when parents are divorced, children become impure public goods to the extent that neither parent has "full access" to them due to court-imposed custodial arrangements (see, e.g., Francesconi and Muthoo, 2011). 
in the future. In our analysis we will concentrate on sophisticated couples. In Section 8 , we will discuss the behavior of naive couples.

We assume that, while married, a couple behave cooperatively and maximize their joint intertemporal utility, $V_{t} \equiv V_{s t}+V_{h t}$. If they divorce, they act non-cooperatively, each maximizing his or her own individual intertemporal utility (see e.g. Weiss and Willis, 1985).

\subsection{Timing, Household Production, Earnings and Consumption}

Period 1. All couples are married throughout the first period and decide how to allocate their unit time endowment between household production $\left(g_{i 1}^{m}\right)$ and labor market activity $\left(\ell_{i 1}^{m}\right)$ in order to maximize their joint intertemporal utility. A production function $v(\cdot, \cdot)$ translates the time-inputs in household production into the family capital good $G_{1}^{m}$. In particular

$$
G_{1}^{m}=v\left(g_{s 1}^{m}, g_{h 1}^{m}\right) .
$$

We assume that $v(\cdot, \cdot)$ is a strictly increasing and strictly concave, and that $v(0,0)=0$ and $\lim _{g_{i} \rightarrow 0} v_{i}\left(g_{s}, g_{h}\right)=\infty$ where $v_{i}$ is the first-order partial derivative with respect to the input of partner $i=s, h$. The second-order partial derivatives are denoted by $v_{i j}$. Our setup allows the spouse' time inputs to be either substitutes $\left(v_{i j}<0\right)$, independent $\left(v_{i j}=0\right)$ or complements $\left(v_{i j}>0\right)$.

Period 2. At the beginning of the second period, the couple's match quality shock $\theta$ is realized, representing a non-economic gain or loss from marriage (see, e.g., Fan, $2001)$. We assume that $\theta$ is drawn from a distribution $F(\cdot)$ with support $(-\infty, \infty)$ and associated density $f(\cdot)$. After $\theta$ is realized, the spouses first decide whether to continue their marriage or to divorce. After that, they decide how to allocate their time. The level of family-specific capital enjoyed, $G_{2}^{k}$, is that carried forward from the first period, $G_{1}^{m}$, plus the amount added through household production in the current period:

$$
G_{2}^{k}=G_{1}^{m}+v\left(g_{s 2}^{k}, g_{h 2}^{k}\right) \quad \text { for } k=m, d .
$$

Note that the level of household production in this period will typically vary with the couple's chosen marital status, $k=m, d .^{3}$

Period 3. We assume that divorced individuals cannot remarry and so continue to live as divorced. We explicitly think of the third period as the stage in a family's life cycle when the children have grown up and left home. Hence, we assume that no

3. In our stylized three-period model, we assume for simplicity that the family capital good is perfectly durable. However, our results would qualitatively also go through in a richer specification with a quasi-durable family public good which is subject to some positive rate of depreciation. The extended version of our model presented in Section 9 allows for such capital depreciation. 
further time is devoted to investment in the children. Instead, individuals spend their entire time endowment on labor market activity. However, both married and divorced couples continue to benefit from the stock of family-specific capital accumulated in the first two periods. Thus,

$$
G_{3}^{k}=G_{2}^{k} \quad \text { for } k=m, d
$$

Earned Income and Consumption. Partner $i$ 's earnings in period $t$ and marital state $k$ are given by $y_{i t}^{k}=\omega_{i} \ell_{i t}^{k}$, where $\omega_{i}$ is the wage rate. Since we are primarily interested in the implications of dynamic inconsistency for family-specific investments rather than in a couple's "sharing rule", we assume that the division of total household earnings between the partners is exogenously determined. In particular, we let $\varphi_{i}$ be the earnings share enjoyed by partner $i$, whereby $\varphi_{s}+\varphi_{h}=1$. We further assume that these shares are independent of marital status and, for reasons that will become clear below, that each partner's consumption share matches his or her share of joint utility of the family capital good post divorce.

Partner $i$ 's consumption level can then be written as

$$
x_{i t}^{k}=\varphi_{i} \sum_{j=s, h} y_{j t}^{k}
$$

with

$$
\varphi_{i}=\frac{\lambda_{i}}{\Lambda}
$$

A leading case is where the woman has, due to custody arrangements, a higher postdivorce enjoyment of the accumulated household public good and also, through child support arrangements, enjoys the larger share of joint income.

\section{Laissez-Faire Allocation}

We begin by characterizing the equilibrium with sophisticated behavior.

Period 3. As noted above, both partners spend their entire time endowment on labor market activity. Thus, we can write the instantaneous utility of partner $i$ in marital status $k=m, d$ as follows:

$$
u_{i 3}^{m}=\varphi_{i} \sum_{j=s, h} \omega_{j}+G_{3}^{m}, \quad \text { and } \quad u_{i 3}^{d}=\varphi_{i} \sum_{j=s, h} \omega_{j}+\lambda_{i} G_{3}^{d},
$$

with $G_{3}^{k}$ given by eq. (6). 
Period 2. At the beginning of the second period the temporary match quality shock $\theta$ is realized and a couple first of all have to decide wether to stay married or to divorce. However, as the gain to marriage also depends on the time allocations made in the second period, we first consider these choices, both within marriage and after divorce.

The instantaneous utility of partner $i$ as married is given by

$$
u_{i 2}^{m}=\varphi_{i} \sum_{j=s, h} \omega_{j}\left(1-g_{j 2}^{m}\right)+G_{2}^{m}+\theta,
$$

where $G_{2}^{m}$ is defined in eq. (5). The couple maximize their joint intertemporal utility from marriage, $\sum_{i=s, h}\left(u_{i 2}^{m}+\beta \delta u_{i 3}^{m}\right)$, where $u_{i 3}^{m}$ and $u_{i 2}^{m}$ are defined in eqs. (9) and (10), respectively. The chosen time allocation, denoted $\left(\hat{g}_{s 2}^{m}, \hat{g}_{h 2}^{m}\right)$, is the unique solution to the following first-order conditions:

$$
\frac{\omega_{i}}{v_{i}\left(\hat{g}_{s 2}^{m}, \hat{g}_{h 2}^{m}\right)}=2(1+\beta \delta) \quad \text { for } i=s, h .
$$

Thus, the marginal cost of each partner adding a further unit of family capital - the left hand side - is set equal to the joint marginal return, where the latter includes the current and discounted future marginal utility to each partner.

The instantaneous utility of partner $i$ as divorced is given by

$$
u_{i 2}^{d}=\varphi_{i} \sum_{j=s, h} \omega_{j}\left(1-g_{j 2}^{d}\right)+\lambda_{i} G_{2}^{d} .
$$

As noted above, divorced partners act non-cooperatively, with partner $i$ maximizing his/her own intertemporal utility, $u_{i 2}^{d}+\beta \delta u_{i 3}^{d}$, where $u_{i 3}^{d}$ and $u_{i 2}^{d}$ are defined in eqs. (9) and (12), respectively. The Nash equilibrium time allocation choices of the divorced spouses, denoted $\left(\hat{g}_{s 2}^{d}, \hat{g}_{h 2}^{d}\right)$, are the unique solution to the following firstorder conditions:

$$
\frac{\omega_{i}}{v_{i}\left(\hat{g}_{s 2}^{d}, \hat{g}_{h 2}^{d}\right)}=\frac{\lambda_{i}}{\varphi_{i}}(1+\beta \delta) \quad \text { for } i=s, h \text {. }
$$

Our assumption in eq. (8) ensures that the time allocation choices of divorced spouses coincide with that which would maximize their joint intertemporal utility. This allows us to abstract away from inefficiencies arising from non-cooperative behavior when analyzing optimal policy design. It also implies that in either marital state, the equilibrium level of household production is produced at the lowest possible cost in terms of total foregone earnings.

It turns out to be convenient to define the difference in equilibrium foregone earnings across the two marital states as:

$$
\hat{\mathcal{C}}_{2} \equiv \sum_{i=s, h} \omega_{i}\left(\hat{g}_{i 2}^{m}-\hat{g}_{i 2}^{d}\right)
$$


As a basis for our subsequent analysis, it is also useful to compare the level of family-specific capital generated through household production in the two possible marital states:

LEMMA 1. For any given level of $G_{1}^{m}$, a couple choose a higher level of household production at $t=2$ if they remain married than if they divorce: $v\left(\hat{g}_{s 2}^{m}, \hat{g}_{h 2}^{m}\right)>$ $v\left(\hat{g}_{s 2}^{d}, \hat{g}_{h 2}^{d}\right)>0$. Thus, they also forego more earnings: $\hat{\mathcal{C}}_{2}>0$.

Consider next the couple's decision whether to remain married or to divorce. This decision takes place after the realization of $\theta$ but before they choose how to allocate their time. A couple will divorce if doing so gives them a larger joint intertemporal utility than remaining married. Thus, a divorce occurs if

$$
\sum_{i=s, h}\left(\hat{u}_{i 2}^{m}+\beta \delta \hat{u}_{i 3}^{m}\right)<\sum_{i=s, h}\left(\hat{u}_{i 2}^{d}+\beta \delta \hat{u}_{i 3}^{d}\right)
$$

where the $\hat{u}_{i t}^{k}$ 's are instantaneous utilities evaluated at $\hat{g}_{s 2}^{k}$ and $\hat{g}_{h 2}^{k}$ respectively for each respective marital status $k=m, d$. Naturally, the couple will divorce if their match quality shock is sufficiently unfavourable. In particular, substituting using eqs. (9), (10) and (12), shows that the couple will divorce if $\theta$ falls below a threshold value, denoted $\hat{\theta}\left(G_{1}^{m}\right)$, the value of which will depend on the level of family-specific capital carried forward from the initial period:

$$
\hat{\theta}\left(G_{1}^{m}\right) \equiv \hat{\mathcal{C}}_{2} / 2-(1+\beta \delta)\left[\hat{G}_{2}^{m}-(\Lambda / 2) \hat{G}_{2}^{d}\right]
$$

where $\hat{G}_{2}^{k}=G_{1}^{m}+v\left(\hat{g}_{s 2}^{k}, \hat{g}_{h 2}^{k}\right)$. It is straightforward to establish that $\hat{\theta}\left(G_{1}^{m}\right)$ is a decreasing function of $G_{1}^{m}$ :

$$
\hat{\theta}^{\prime}\left(G_{1}^{m}\right)=-(1+\beta \delta)(1-\Lambda / 2)<0 .
$$

From the perspective of the first period, the probability of divorce, which can be written as $F\left(\hat{\theta}\left(G_{1}^{m}\right)\right)$, is thus endogenous since it decreases with the family-specific capital the couple accumulates in that period.

Period 1. Partner $i$ 's instantaneous utility in the first period is given by

$$
u_{i 1}^{m}=\varphi_{i} \sum_{j=s, h} \omega_{j}\left(1-g_{j 1}^{m}\right)+G_{1}^{m},
$$

where $G_{1}^{m}$ is given by eq. (4). The couple choose their time allocation to maximize their joint intertemporal utility, $V_{s 1}+V_{h 1}$, correctly anticipating their own future behavior, with

$$
V_{i 1}=u_{i 1}^{m}+\beta \delta\left\{\mathbf{E}_{\theta}\left(\hat{u}_{i 2}^{m}+\delta \hat{u}_{i 3}^{m} \mid \theta>\hat{\theta}\right)[1-F(\hat{\theta})]+\left(\hat{u}_{i 2}^{d}+\delta \hat{u}_{i 3}^{d}\right) F(\hat{\theta})\right\},
$$


where $\hat{\theta}=\hat{\theta}\left(G_{1}^{m}\right)$ and $\mathbf{E}_{\theta}$ is the expectations operator, with expectations taken over $\theta$. The first term in the curly brackets reflects a couple's continuation value upon entering the second period conditional on the marriage surviving and the second term is the corresponding value conditional on divorcing.

LEMMA 2. The time allocation chosen by a couple at $t=1$, denoted $\left(\hat{g}_{s 1}^{m}, \hat{g}_{h 1}^{m}\right)$, is the unique solution to the following first-order conditions:

$$
\frac{\omega_{i}}{v_{i}\left(\hat{g}_{s 1}^{m}, \hat{g}_{h 1}^{m}\right)}=2+\beta \delta(1+\delta)\{2-(2-\Lambda)[F(\hat{\theta})-\chi f(\hat{\theta})]\} \quad \text { for } i=s, h
$$

where $\hat{\theta}=\hat{\theta}\left(\hat{G}_{1}^{m}\right)$ defined as in eq. (16) with $\hat{G}_{1}^{m}=v\left(\hat{g}_{s 1}^{m}, \hat{g}_{h 1}^{m}\right)$, and where

$$
\chi \equiv \frac{(1-\beta) \delta(1+\beta \delta)\left(\hat{G}_{2}^{m}-(\Lambda / 2) \hat{G}_{2}^{d}\right)}{1+\delta}>0
$$

with $\hat{G}_{2}^{k}=\hat{G}_{1}^{m}+v\left(\hat{g}_{s 2}^{k}, \hat{g}_{h 2}^{k}\right)$ for $k=m, d$.

Decomposing eq. (20) reveals that a couple has five sources of (dis)incentives to invest time in the family capital good. First, an increase in $G_{1}^{m}$ increases a couple's joint lifetime benefits from family-specific capital conditional on the marriage remaining intact in the second period. This acts as an incentive to make family-specific investments and is given by $2[1+\beta \delta(1+\delta)]$. Second, the lowered enjoyment of the capital good in the case of divorce acts as a disincentive to invest and is captured by $-\beta \delta(1+\delta)(2-\Lambda) F(\hat{\theta})$.

Third, an increased accumulation of family capital good in the first period, makes a couple more prone to remain married in the second period which lowers the expected value of the match quality if the marriage remains intact. This "marital quality effect" acts as a disincentive to invest in the family capital good and is given by $-2 \beta \delta \hat{\theta} f(\hat{\theta}) \hat{\theta}^{\prime}$. Fourth, counteracting this effect is the direct utility gain that comes with an increase in the probability of the marriage remaining intact. This "endogenous divorce effect" increases incentives to make family-specific investments and is given by $-\beta \delta f(\hat{\theta}) \hat{\theta}^{\prime}\left[(1+\delta)\left(2 \hat{G}_{2}^{m}-\Lambda \hat{G}_{2}^{d}\right)-\hat{\mathcal{C}}_{2}\right]$. Subtracting the marital quality effect from the endogenous divorce effect using the expressions for $\hat{\theta}$ and $\hat{\theta}^{\prime}$ derived in eqs. (16)-(17), we have

$$
\beta \delta(1+\delta)(2-\Lambda) \chi f(\hat{\theta})>0 .
$$

In words, given that the couple are present-biased, the positive "endogenous divorce effect" dominates the negative "marital quality effect". For reasons that will become clear shortly, we will refer to this term as the "sophistication effect". Note that this effect would vanish in the absence of present bias: $\beta \rightarrow 1$ implies $\chi \rightarrow 0$.

Finally, as before, the left hand side captures the marginal cost of generating an additional unit of the family-specific capital through an increase in the time input into household production by partner $i$. 


\section{First-Best Allocation and Inefficiency of Laissez-Faire under Present-Bias}

We follow O'Donoghue and Rabin (2006) and treat individuals' preference for shortterm gratification as an error, leading to a self-control problem when $\beta<1$. When viewed from an ex ante perspective, the first-best allocation maximizes the pure $\delta$ discounted joint expected utilities. Since the structure of the problem remains the same, but with $\beta$ set to unity throughout, we can directly summarize a couple's efficient behavior. In the second period, the first-best time allocations by marital status $k=m, d$, denoted $\left(\tilde{g}_{s 2}^{k}, \tilde{g}_{h 2}^{k}\right)$, satisfy

$$
\frac{\omega_{i}}{v_{i}\left(\tilde{g}_{s 2}^{k}, \tilde{g}_{h 2}^{k}\right)}=\left\{\begin{array}{ll}
2(1+\delta) & \text { if } k=m \\
\Lambda(1+\delta) & \text { if } k=d
\end{array} \quad \text { for } i=s, h .\right.
$$

The efficient match quality threshold, given an arbitrary $G_{1}^{m}$, satisfies

$$
\tilde{\theta}\left(G_{1}^{m}\right) \equiv \tilde{\mathcal{C}}_{2} / 2-(1+\delta)\left[\tilde{G}_{2}^{m}-(\Lambda / 2) \tilde{G}_{2}^{d}\right],
$$

where $\tilde{\mathcal{C}}_{2}=\sum_{i=s, h} \omega_{i}\left(\tilde{g}_{i 2}^{m}-\tilde{g}_{i 2}^{d}\right)$ and $\tilde{G}_{2}^{k}=G_{1}^{m}+v\left(\tilde{g}_{s 2}^{k}, \tilde{g}_{h 2}^{k}\right)$.

In the initial period, a couple's first-best time allocation, denoted $\left(\tilde{g}_{s 1}^{m}, \tilde{g}_{h 1}^{m}\right)$, is the unique solution to:

$$
\frac{\omega_{i}}{v_{i}\left(\tilde{g}_{s 1}^{m}, \tilde{g}_{h 1}^{m}\right)}=2+\delta(1+\delta)[2-(2-\Lambda) F(\tilde{\theta})] \quad \text { for } i=s, h,
$$

where $\tilde{\theta}=\tilde{\theta}\left(\tilde{G}_{1}^{m}\right)$ with $\tilde{G}_{1}^{m}=v\left(\tilde{g}_{s 1}^{m}, \tilde{g}_{h 1}^{m}\right)$. Thus, the probability of divorce in the first-best allocation can be written as $F\left(\tilde{\theta}\left(\tilde{G}_{1}^{m}\right)\right)$.

How does a bias for the present distort a couple's behavior as compared to the firstbest choices that would have maximized their pure $\delta$-discounted joint intertemporal utility? Consider first a couple's second-period choices. The following result holds globally for any degree of present bias (i.e. for any $\beta<1$ ):

Proposition 1 (Second-Period Choices). For any given level of $G_{1}^{m}$, a present bias causes a couple at $t=2$ to:

(a) choose an inefficiently low level of household production in each marital state: $v\left(\hat{g}_{s 2}^{k}, \hat{g}_{h 2}^{k}\right)<v\left(\tilde{g}_{s 2}^{k}, \tilde{g}_{h 2}^{k}\right)$ for $k=m, d$.

(b) "over-divorce"-i.e., to break up for a larger set of match quality realizations than in the first-best allocation: $\hat{\theta}\left(G_{1}^{m}\right)>\tilde{\theta}\left(G_{1}^{m}\right)$.

That present-biasedness causes a couple to underinvest in the family-specific capital is hardly surprising given that they place too little weight on its future benefits. 
Perhaps more interesting is the over-divorcing result. On the one hand, divorce has two "short-term gratification" components: it allows the couple to avoid a temporary unfavorable match quality shock and they can enjoy more current consumption as they will forego less earnings to produce the household capital good. On the other hand, divorce has two "long-term" effects, the payoff consequences of which persist into the final period: it reduces the amount of family-specific capital that the couple accumulate and it also reduces their total enjoyment from their family capital good. Present-biased couples "over-divorce" because they overreact to the short-term gratification components of divorce relative to the two permanent effects.

The impact of present bias on a couple's first-period investment is less obvious. Two opposing effects can be identified. As in the second period, a present bias directly causes the couple place too little weight on future relative to current payoffs which generates a tendency for underinvestment. However, being sophisticated, the couple are aware that their present bias will make them too prone to divorce in the following period. This provides them with a strategic investment motive: by investing more in the first period, they can reduce their divorce risk in the second period. Formally, the strategic investment motive is captured by the sophistication effect in eq. (22) which is not present in the first-order condition characterizing the efficient investment level.

We now ask whether the direct present-bias effect dominates the sophistication effect or vice versa. In order to derive a clear-cut result, we will consider how the introduction of present bias into the couples' preferences - that is, a marginal reduction in $\beta$ away from unity - affects the level of first-period household production.

Proposition 2 (First-Period Household Production). At $t=1$, the introduction of present bias causes a couple to choose an inefficiently low level of household production: $v\left(\hat{g}_{s 1}^{m}, \hat{g}_{h 1}^{m}\right)<v\left(\tilde{g}_{s 1}^{k}, \tilde{g}_{h 1}^{k}\right)$.

Thus, the introduction of present bias will cause couples to exit the first period with an inefficiently low level of family-specific capital. A present bias therefore increases the equilibrium divorce risk through two channels: it does so directly by making the couple more prone to divorce for any given level of family capital, and also indirectly by reducing the accumulation of family-specific capital in the initial period.

One caveat is that the above result is only a "local" one as $\beta$ is arbitrarily close to unity. There are sufficient conditions under which the result can be generalized to hold for any degree of present bias. One particularly simple condition concerns the probability density function $f$ :

COROLlary 1. Suppose that the match quality shock $\theta$ is drawn from a uniform probability density function: $\theta \sim \mathcal{U}(\underline{\theta}, \bar{\theta})$. At $t=1$, a couple will then choose an inefficiently low level of household production for any degree of present bias.

The results above have naturally been stated in terms of a couple's total level of household production rather than in terms of the spouses' individual time inputs. As 
noted earlier, for any chosen level of household production, the spouses' time inputs minimize the cost in terms of total foregone earnings. ${ }^{4}$ This means that, as long as neither partner's time is an "inferior" input, statements on the levels of household production carry over to individual time inputs. Neither partner's time input can be inferior if the household production function either exhibits complementarity or independence (i.e., when $v_{s h} \geq 0$ ). If the time inputs are substitutes (i.e., when $v_{s h}<0$ ), one partner's time input may be inferior.

\section{Privately Optimal Marriage Contracts}

In the Introduction we highlighted how, in various cultures and religions around the world, couples enter into marriage on contractual terms that make divorce a costly option. While standard models of household behavior have difficulties in rationalizing this type of marriage contracts, our theory suggests that couples who expect themselves to behave with a present bias may find them privately optimal. To see this, we now add an additional ex ante stage, $t=0$, to the model.

We will think of this ex ante stage as the time of marriage, before any family investments commence, and we will explore if a marrying couple can be made better off with a marital contract obliging them to pay a positive monetary penalty $\zeta$ in the event of divorce. Framed differently, we may also think of a society deciding on opting for legislation that makes divorce more costly. The remainder of the game then follows the same structure as in the baseline model, but now includes the divorce penalty.

Consider the couple's joint intertemporal utility as viewed from the ex ante stage when a divorce penalty $\zeta$ is in operation. This can be written as $V_{0}=V_{s 0}+V_{h 0}$, where:

$$
V_{i 0}=\beta \delta\left\{\hat{u}_{i 1}^{m}+\delta\left[\mathbf{E}_{\theta}\left(\hat{u}_{i 2}^{m}+\delta \hat{u}_{i 3}^{m} \mid \theta>\hat{\theta}\right)[1-F(\hat{\theta})]+\left(\hat{u}_{i 2}^{d}-\varphi_{i} \zeta+\delta \hat{u}_{i 3}^{d}\right) F(\hat{\theta})\right]\right\},
$$

and where the match quality threshold level $\hat{\theta}$ depends on $\zeta$ not only directly but also indirectly via its impact on the couple's choice of first period level of household production. We will assume that a couple responds to the introduction of positive divorce penalty by increasing their first period level of household production, $\partial \hat{G}_{1}^{m} /\left.\partial \zeta\right|_{\zeta=0}>0$. This can be shown to hold for the case of a uniformly distributed match quality $\theta \sim \mathcal{U}(\underline{\theta}, \bar{\theta})$, but can also be expected to hold much more generally. We then obtain:

4. Note that this holds not only in marriage, but also after divorce due to the assumption in eq. (8). 


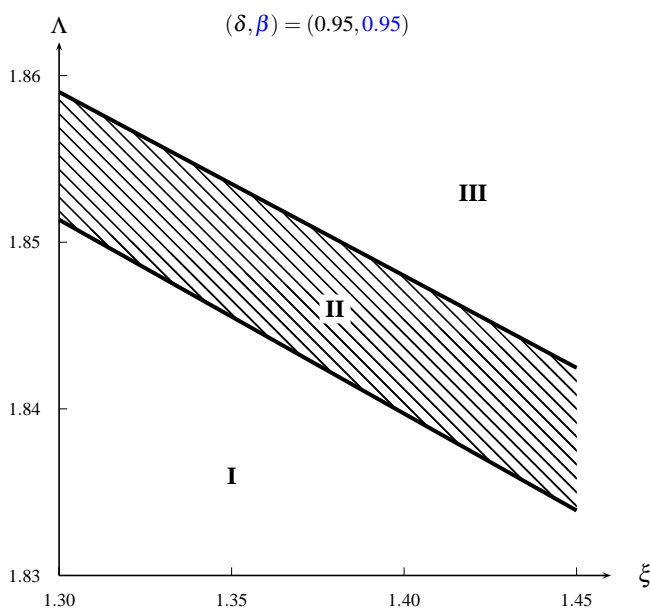

(A) Privately Optimal Marriage Contracts in the $(\Lambda, \xi)$-space

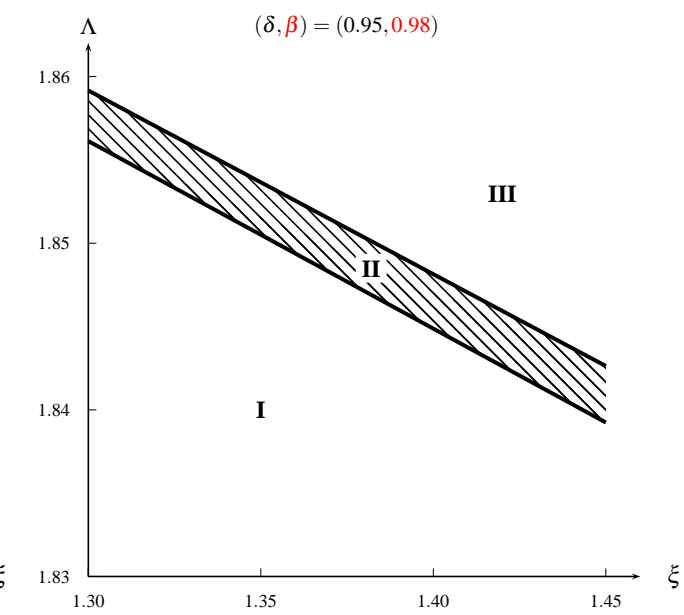

(в) A reduction in present bias

Figure 1

A Welfare Improving Divorce Penalty

Proposition 3 (Welfare-Improving Divorce Penalty). If

$$
F(\hat{\theta})<\frac{(1+\delta)\left\{\left.[2+(2-\Lambda) f(\hat{\theta}) \chi](1-\beta)(1+\beta \delta) \frac{\partial \hat{G}_{1}^{m}}{\partial \zeta}\right|_{\zeta=0}+\chi f(\hat{\theta})\right\}}{(1+\beta \delta)\left[1+\left.(2-\Lambda)(1-\beta)(1+\delta) \frac{\partial \hat{G}_{1}^{m}}{\partial \zeta}\right|_{\zeta=0}\right]}
$$

holds at the laissez-faire equilibrium, then introducing a positive divorce penalty $\zeta>0$ into the marriage contract will increase the couple's joint ex ante expected utility.

The following provides an intuition. The introduction of a divorce penalty mitigates the over-divorce distortion in the second period as well as the extent of underinvestment in the first period, thus modifying a present-biased couple's behavior in the efficient direction. ${ }^{5}$ However, a divorce penalty also comes with a first-order cost effect which is proportional to the risk of divorce. Hence, if $\beta$ is only marginally below unity, a divorce penalty cannot improve a couples' ex-ante utility as their behavior is already close to efficient, implying that the first-order cost effect dominates. ${ }^{6}$ But if the degree of present bias is more substantial and the baseline divorce risk is low, the impact of the divorce penalty on future behavior can dominate the cost effect.

5. Note that when, when $\zeta=0, V_{0}$ is proportional to the pure $\delta$-discounted joint utility that is maximized by the efficient allocation.

6. Formally, in the limit where $\beta \rightarrow 1$, the right hand side of (27) goes to zero. To see this, recall that $\chi$ also goes to zero, see eq. (21). 
This is illustrated in Figure 1 based on a model specification that gives rise to closed form solutions. In particular, it is assumed that $\theta \sim \mathcal{U}(-2,0)$ and that the household production function is given by $v\left(g_{s t}, g_{h t}\right)=\sqrt{g_{s t}}+\sqrt{g_{h t}}$. Under this assumption, the cost of achieving a level of household production $v$ can be written as $C(v)=\frac{1}{2} \xi v^{2}$, where $\xi$ is an increasing function of $\omega_{s}$ and $\omega_{h}$.

In Panel $\mathrm{A}$, we set $(\delta, \beta)=(0.95,0.95)$ and examine couples' incentives to accept a divorce penalty as part of their marital contract in the $(\Lambda, \xi)$-space. ${ }^{7}$ There are three regions to consider. Region $I$ is irrelevant for the purpose of our analysis, in that for parameter values in this region the equilibrium divorce rate is zero. In Region II, the efficiency-enhancing effect of a divorce penalty dominates the first-order cost effect. Thus, it will be privately optimal for couples to accept a marriage contract making divorce a costly option. Notice that Region II represents parameter values for which the equilibrium divorce rate is relatively low. Put differently, the gains from marriage over divorce are relatively large, either because the opportunity cost of home production is low, or because the rate at which couples can enjoy the family capital good after a divorce is low. For $(\Lambda, \xi)$-combinations in Region III, the equilibrium divorce rate is larger. As a consequence, the efficiency-enhancing effect of a divorce penalty is too small relative to the first-order cost effect, and couples are better off to leave divorce as costless option. Panel B presents results for a comparative-statics exercise in which the degree of present bias is lowered. As would be expected, this has the effect of reducing the set parameter values under which couples benefit from a divorce penalty.

Overall, the main message here is that present-biased couples may have an incentive to make divorce a costly option, and that this incentive is particularly pronounced in environments in which the equilibrium divorce rate is naturally low.

\section{Efficiency-Restoring Policy}

A marital contract that involves a divorce cost may allow a present-biased couple to get closer to their first-best behavior, but will not achieve full efficiency. We now show that full efficiency can be restored through policy provided there are sufficient policy instruments. In particular, the efficiency-restoring policy will in general vary over the couple's marital lifecycle.

We consider a set of policy instruments which corresponds to the set of decisions taken by couples, most notably their time allocations and potential divorce decision. We thus let $\tau_{t}$ be a proportional tax on labor earnings in period $t$, and let $\eta$ be a divorce tax payable by a couple who choose to divorce. All expected tax proceeds are

7. In Section 9 we will use these time preference parameter values when calibrating the extended version of our model to the US economy. 
given to the couple as a lump-sum transfer $\alpha_{t}$ at the outset of each period, before the couple take any decisions. We then have the following:

Proposition 4 (Efficiency-Restoring Policy). The first-best allocation can be implemented by a policy scheme with the following elements:

(a) At $t=2$, there are taxes on labor earnings and on divorce given by:

$$
\hat{\tau}_{2}=\frac{\delta(1-\beta)}{1+\delta} \quad \text { and } \quad \hat{\eta}=(1-\beta) \delta\left[2 \tilde{G}_{2}^{m}-\Lambda \tilde{G}_{2}^{d}-\tilde{\mathcal{C}}_{2} /(1+\delta)\right] .
$$

The lump-sum transfer allocated to couples at outset of the period (i.e., before $\theta$ is realized) is given by:

$$
\hat{\alpha}_{2}=\hat{\tau}_{2} \sum_{i=s, h} \omega_{i}\left(1-\tilde{g}_{i 2}^{m}\right)+F(\tilde{\theta})\left[\hat{\tau}_{2} \tilde{\mathcal{C}}_{2}+\hat{\eta}\right],
$$

where $\tilde{\theta}=\tilde{\theta}\left(\tilde{G}_{1}^{m}\right), \tilde{G}_{2}^{k}=\tilde{G}_{1}^{m}+v\left(\tilde{g}_{s 2}^{k}, \tilde{g}_{h 2}^{k}\right)$ and $\tilde{\mathcal{C}}_{2}=\sum_{i=s, h} \omega_{i}\left(\tilde{g}_{i 2}^{m}-\tilde{g}_{i 2}^{d}\right)$.

(b) At $t=1$, there is a tax on labor earnings given by:

$$
\hat{\tau}_{1}=\frac{(1-\beta) \delta(1+\delta)[2-(2-\Lambda) F(\tilde{\theta})]}{2+\delta(1+\delta)[2-(2-\Lambda) F(\tilde{\theta})]} .
$$

The lump-sum transfer allocated to a couple at the outset of the period is given by:

$$
\hat{\alpha}_{1}=\hat{\tau}_{1} \sum_{i=s, h} \omega_{i}\left(1-\tilde{g}_{i 1}^{m}\right) .
$$

A number of points are worth noting. First, the lump-sum returning of the expected tax revenues in each period ensures that the policy is revenue neutral. Second, the efficiency-restoring earnings tax is gender-neutral: even if spouses differ in their labor market and household productivities, they face the same tax rate on their earnings at any moment in time. Third, the earnings tax $\hat{\tau}_{t}$ that the couple face when married varies over time, and it does so for two reasons. On the one hand, family investments made in the first period are enjoyed over a longer time horizon than those made in the second period. On the other hand, they are made under the risk of future divorce. The earnings $\operatorname{tax} \hat{\tau}_{2}$ is here also independent of marital status; this is due to the assumption of a zero divorce risk in the final period. In Section 9, we show how the expression for $\hat{\tau}_{1}$ generalizes to an environment with an arbitrary number of periods and show how the efficiency-restoring earnings tax on married couples varies over time due to a horizon effect and a future-divorce-risk effect. Fourth, the optimal divorce tax is positive. Even if couples are induced by policy to choose efficient time allocations, they still overreact to negative match-quality shocks and the tax on divorce corrects for this. 
Overall, the results presented here provide a new perspective for research into the optimal taxation of couples. The existing literature has mainly focused on the design of gender-specific tax schedules (e.g., Boskin and Sheshinski, 1983; Alesina et al., 2011; Immervoll et al., 2011; Meier and Rainer, 2015). A conventional result that emerges from these studies is that the spouse with the higher labor supply elasticity - typically the secondary earner - should be taxed at a lower rate. With time-inconsistent couples, there will be additional drivers in the design of optimal income tax schedules that call for gender-neutral but life-cycle-dependent earnings taxes for married spouses.

\section{Naive Couples}

So far, we have focused on sophisticated behavior by couples who are aware of their time-inconsistent preferences. The literature contrasts this to naive behavior by individuals who are not aware of their self-control problem. A naive individual acts at any moment in time - on a preference for instant gratification, but fails to foresee that she or he will do so in the future. The distinction is easily understood in the current three-period environment. In the initial period, a naive couple, while overweighting their current utility, expect that they will behave efficiently in the following period conditional on their first-period choices. However, upon entering the second period, they will once again overweight the current period whereby their behavior, from that point, will coincide with that of a sophisticated couple. ${ }^{8}$

It is straightforward to show that naive couples suffer from an "optimism bias" both regarding their marriage survival probability and their future investments in familyspecific capital. Part (1) of the Proposition below notes that naive couples ex-ante overestimate the amount of time they will ex-post allocate to home production as they fail to foresee that, when the second period arrives, they will once again be presentbiased. It further implies that naive couples underestimate their future probability of divorce as they fail to foresee that their future desire for instant gratification will lead them to seek to avoid adverse match quality shocks by divorcing and also to underinvest. A naive couple will therefore find themselves divorcing under some match quality realizations at which they anticipated their marriage to survive.

A common result in the literature is that individuals behave more inefficiently if they are naive rather than sophisticated. For example, a seminal result by O'Donoghue and Rabin (1999a) suggests that naive individuals are more inclined to procrastinate with respect to immediate-cost activities than sophisticated ones. Curiously, this is not necessarily the case in the current setting. When making their first period

\footnotetext{
8. A naive couple will correctly anticipate their choices within any current period. Hence, for instance, when they are choosing whether or not to remain married at the outset of the second period, they correctly anticipate what time allocation choices they would make in that period in each potential marital state.
} 
time allocation decision, a naive couple base that on their over-optimistic marriage survival probability which strengthens their incentives to invest. However, even with this optimism bias they still invest less than the first best level. We summarize the above discussion in the following proposition:

Proposition 5 (Naive Couples).

1. For a given level of $G_{1}^{m}$ :

(a) A naive couple's expectations at $t=1$ about their behaviour at $t=2$ is that they will adopt the efficient threshold rule, $\tilde{\theta}\left(G_{1}^{m}\right)$ for divorce and will choose the efficient time allocation $\left(\tilde{g}_{s 2}^{k}, \tilde{g}_{h 2}^{k}\right)$ in each marital state, $k=m, d$.

(b) As their equilibrium threshold rule will correspond to $\hat{\theta}\left(G_{1}^{m}\right)$ and their time allocation choice will correspond to $\left(\hat{g}_{s 2}^{k}, \hat{g}_{h 2}^{k}\right)$ for $k=m, d$, there will be a positive probability of an unanticipated divorce, $F\left(\hat{\theta}\left(G_{1}^{m}\right)\right)>F\left(\tilde{\theta}\left(G_{1}^{m}\right)\right)$, and their level of household production will, in each marital state, be lower than anticipated, $v\left(\hat{g}_{s 2}^{k}, \hat{g}_{h 2}^{k}\right)<v\left(\tilde{g}_{s 2}^{k}, \tilde{g}_{h 2}^{k}\right)$.

2. The equilibrium time allocation chosen by a naive couple at $t=1$, denoted $\left(\bar{g}_{s 1}^{m}, \bar{g}_{h 1}^{m}\right)$, is the unique solution to the following first-order conditions:

$$
\frac{\omega_{i}}{v_{i}\left(\bar{g}_{s 1}^{m}, \bar{g}_{h 1}^{m}\right)}=2+\beta \delta(1+\delta)[2-(2-\Lambda) F(\bar{\theta})] \quad \text { for } i=s, h,
$$

where $\bar{\theta}=\tilde{\theta}\left(\bar{G}_{1}^{m}\right)$ with $\bar{G}_{1}^{m}=v\left(\bar{g}_{s 1}^{m}, \bar{g}_{h 1}^{m}\right)$. As a result, a naive couple will choose an inefficiently low level of household production for any degree of present bias: $v\left(\bar{g}_{s 1}^{m}, \bar{g}_{h 1}^{m}\right)<v\left(\tilde{g}_{s 1}^{k}, \tilde{g}_{h 1}^{k}\right)$.

So, whereas sophisticated couples have a positive strategic motive boosting their first period investment, the investments by naives are boosted by marriagesurvival-optimism. The latters' optimism bias, if anything, typically provides stronger investment incentives than the strategic incentives for sophisticated couples.

Proposition 6. At $t=1$, a naive couple will choose a higher (lower) level of household production than a sophisticated couple if and only if:

$$
\frac{F(\hat{\theta})-F(\bar{\theta})}{\hat{\theta}-\bar{\theta}}>(<) \kappa f(\hat{\theta})
$$

where $\kappa \simeq(1+\beta \delta) /(1+\delta) \leq 1$

This result has an intuitive explanation. On the one hand, if $f(\hat{\theta})$ is large, an increase in $G_{1}^{m}$ leads to a large increase in the equilibrium marriage survival rate, implying a strong strategic investment motive for a sophisticated couple. The left hand side of eq. (33), on the other hand, effectively measures the rate at which a 
naive couple's misperception of their own future divorce behaviour generates marriage survival optimism which, if large, implies a large optimism bias. But, trivially, the left hand side of eq. (33) is, to a first order approximation, equal to $f(\hat{\theta})$ whereby it follows from $\kappa<1$ (whenever $\beta<1$ ) that the optimism bias effect is typically stronger than the sophistication effect. ${ }^{9}$ In our numerical examples, based on a modest degree of present bias - and hence $\kappa$ close to unity - we have found the behavior under sophistication and naivety to be very similar. ${ }^{10}$

It should further be noted that, as a naive couple expect themselves to behave efficiently in the future, they will not agree to a marriage contract that imposes a divorce cost.

\section{An Extended and Calibrated Model}

We now extend the model to a $T$-period setting which we calibrate to the US economy. Doing so allows for a richer set of family paths and enables us to address key quantitative questions: what impact does an empirically relevant level of present bias have on family behavior and outcomes? And what structure and level of policy is required to restore efficiency?

The family-specific capital enjoyed in period $t$ is, as before, $G_{t}+v\left(g_{s t}, g_{h t}\right)$ where $G_{t}$ is the amount of capital carried forward from the previous period. We now also allow for capital depreciation by setting

$$
G_{t}=\gamma\left[G_{t-1}+v\left(g_{s, t-1}, g_{h, t-1}\right)\right]
$$

where $\gamma \in(0,1)$ is the capital carry-forward rate. In line with our interpretation of the capital good as investments in children, we assume that the investment process terminates at some $T_{0}<T$. In each period, a couple experience a match quality shock $\theta_{t}$, which is i.i.d. across periods and drawn from a distribution $F(\cdot)$. An adverse temporary shock may induce a couple to divorce and if they do so they remain divorced forever. Thus, there will be couples who find themselves divorced but still making investments and, conversely, couples who find themselves still married but with no further investments to make. We will focus on sophisticated behaviour.

The efficiency-restoring policy will involve (i) an earnings tax $\tau_{t}^{k}$ which generally varies with marital status, $k=m, d$, and marriage duration $t \leq T_{0}$, and (ii) a divorce $\operatorname{tax} \eta_{t}$ that also varies with duration $t \leq T{ }^{11}$

9. The latter can still be stronger if the density is locally increasing, that is, if $F(\hat{\theta})$ is locally convex.

10. Indeed, one can show that naive and sophisticated couples respond to the introduction of a present bias in the same way in terms of their first period investments.

11. No earnings tax is imposed at $t>T_{0}$ since there are no time-allocation decisions to be made once the investment process has terminated. The divorce tax however is applicable across all periods. 
The post-divorce earnings tax has a simple analytical solution:

$$
\hat{\tau}_{t}^{d}=(1-\beta) \frac{\sum_{n=1}^{T-t}(\delta \gamma)^{n}}{1+\sum_{n=1}^{T-t}(\delta \gamma)^{n}} \quad \text { for } \quad t \leq T_{0}
$$

which generalizes eq. (28). This shows that the earnings tax, at any duration $t$ (within the investment phase), is proportional to the degree of present bias. It also varies with $t$ as a longer marriage duration implies a shorter remaining horizon. However, given that there are several post-investment periods the ratio on the right hand side of eq. (35) will be close to $\delta \gamma$ for any investment period $t \leq T_{0}$. Hence while $\hat{\tau}_{t}^{d}$ is decreasing over time due to the horizon effect, it is, for reasonable $\delta$ and $\gamma$, very close to $\delta \gamma(1-\beta)$ throughout a couple's investment phase.

A similar expression, though somewhat more involved, can be provided for the earnings tax facing married couples:

$$
\hat{\tau}_{t}^{m}=(1-\beta) \frac{\gamma \delta \tilde{V}_{t+1}^{\prime}}{2+\gamma \delta V_{t+1}^{\prime}} \quad \text { for } t \leq T_{0}
$$

where

$$
\tilde{V}_{t}^{\prime}=\sum_{n=0}^{T-t}(\delta \gamma)^{n}\left\{2 \prod_{j=0}^{n}\left[1-F\left(\tilde{\theta}_{t+j}\right)\right]+\Lambda\left[1-\prod_{j=0}^{n}\left[1-F\left(\tilde{\theta}_{t+j}\right)\right]\right]\right\}
$$

with $\tilde{\theta}_{t+j}=\tilde{\theta}_{t+j}\left(\tilde{G}_{t+j}\right)$, captures the joint marginal value of capital, in the efficient allocation, to a couple entering period $t$ as married. ${ }^{12}$ This generalizes both eq. (30) and eq. (28) in the three-period model. It is straightforward to show that $\hat{\tau}_{t}^{m} \leq \hat{\tau}_{t}^{d}$, with the difference obtaining from the fact that $\Lambda<2$ and positive future divorce risk. In particular, if either (i) $\Lambda \rightarrow 2$, or (ii) at $t$, there was no future divorce risk, then the earnings tax at $t$ would coincide across marital status. ${ }^{13}$ When we calibrate the model we obtain that $\Lambda / 2 \geq 0.9$ (see below). From this it follows that the difference between $\hat{\tau}_{t}^{m}$ and $\hat{\tau}_{t}^{d}$ will be fairly small, and both will be close to $(1-\beta) \gamma \delta$ throughout the couple's investment phase.

We assume a normal distribution for the match quality shocks, $\theta_{t} \sim N\left(\mu_{\theta}, \sigma_{\theta}\right)$, and a simple additively separable iso-elastic specification for the household production function,

$$
v\left(g_{s t}, g_{h t}\right)=a g_{s t}^{b}+a g_{h t}^{b}
$$

\footnotetext{
As in the three-period model, the efficiency-restoring policy also involves a transfer to each couple at the beginning of each period that corresponds to the expected total tax paid in that period.

12. Intuitively, an extra unit of capital increases a couple's joint utility by 2 in any remaining period in which the couple are still married and by $\Lambda$ in any period in which they are divorced. The expression captures this while accounting also for discounting and capital depreciation.
}

13. This explains why, in the three period model, we obtained that $\hat{\tau}_{2}^{m}=\hat{\tau}_{2}^{d}$ as we assumed zero divorce risk at $t=3$. 
where $a, b>0$. We set $T=40$, thus effectively capturing the time from the median age at first marriage until retirement age. ${ }^{14,15} \mathrm{~A}$ number of parameters are set based on the literature, including $\beta$ and $\delta$. For the latter, a large macro literature, following Prescott (1986), have argued that a reasonable range for the annual discount rates is 2-7 percent so we fix a value in the middle of this range, $\delta=0.95$. For $\beta$ there have been recent findings of little or no present bias in experiments with monetary payments (e.g., Andreoni and Sprenger, 2012), but clear present bias in the experiments based on real effort tasks (Augenblick, Niederle and Sprenger, 2013). Furthermore, it is not clear whether joint decision-making by couples or other groups of individuals are more or less time-consistent than is individual decision-making (Jackson and Yariv, 2015). Contrasting choices made separately and jointly, Carlsson and Yang (2013) find no evidence that married couples behave systematically more time-consistent when making joint decisions than when making individual ones. The estimates of Augenblick, Niederle and Sprenger (2013) suggest values of $\beta$ of around 0.9, which would seem like a natural lower bound for the current exercise and hence we impose a conservative value of $\beta=0.95$.

We set the length of the investment phase $T_{0}$ to 20 years, corresponding to the average school leaving age in the US (OECD, 2008). The "gender pay gap" is generally defined as the ratio of female to male median yearly earnings among full-time, yearround workers. In 2013, the female-to-male earnings ratio was 82 percent (BLS, 2014). Hence we normalize the male wage to unity, $w_{h}=1$, and set the female wage to $w_{s}=0.82$. Based on the literature, we set a modest degree of human capital depreciation, $\gamma=0.975$ (Manuelli, Seshadri and Shin, 2012). We further assume a wife continues to fully enjoy the family-specific capital post divorce, $\lambda_{s}=1$, but not the husband.

We calibrate the remaining parameters: the household production technology parameters $a$ and $b$, the location and spread of the distribution of match quality shocks $\mu_{\theta}$ and $\sigma_{\theta}$, and the husband's post-divorce enjoyment of the capital good, $\lambda_{h}$. To do so we use empirical stylized facts on how couples with children allocate their time, on marriage survival rates, on the impact divorce have on kids' outcomes, and on the impact of children leaving on the divorce risk.

Combining data on labor force participation from the U.S. Bureau of Labor Statistics with time use data from the American Time Use Survey, we use as a stylized fact that married women and men with children in the household spend on average 64 percent and 33 percent of (non-leisure) time on household work respectively. ${ }^{16}$

14. The median age at first marriage currently, according to the US Census Bureau, stands at about 27 for women and 29 for men.

15. We include a further 10 "retirement" periods during which a couple cannot divorce. The purpose of this is to prevent a sharp increase in the divorce hazard for a couple that approache $T$. Indeed, otherwise the future component of the gain to marriage would become quickly dominated by the match quality shocks.

16. BLS Report 1052 (2014, Tables 5, 6 and 21) give fraction of married women with children under the age of 18 who were in the labor force and the fraction working full time, along with the 
TABle 1. Baseline Calibration of the Extended Dynamic Model

\begin{tabular}{lccc}
\hline & Parameter/Stylized Fact & Value & Source \\
\hline$\delta$ & Annual discount date & 0.95 & Literature \\
$\beta$ & Present-bias factor & 0.95 & Literature \\
$\omega_{h}$ & Male wage rate & 1.00 & Normalized \\
$\omega_{s}$ & Female wage rate & 0.82 & BLS \\
$\gamma$ & Capital carry-forward rate & 0.975 & Literature \\
\hline$a$ & Investment efficiency & 0.042 & Matched \\
$b$ & Investment elasticity & 0.70 & Matched \\
$\lambda_{s}$ & Female post-divorce utility & 1 & Fixed \\
$\lambda_{h}$ & Male post-divorce utility & 0.84 & Matched \\
$\mu_{\theta}$ & Match quality location & -0.01 & Matched \\
$\sigma_{\theta}$ & Match quality spread & 0.90 & Matched \\
\hline & Marriage survival at 10 years & 0.68 & NCHS \\
& "Empty nest" divorce effect & 0.75 & Literature \\
& Married males' labour market time & 0.67 & BLS, ATUS \\
& Married females' labour market time & 0.36 & BLS, ATUS \\
& Maximum impact divorce at 10 years & 0.15 & Literature \\
\hline
\end{tabular}

Turning to marriage survival rates, in the latest figures, the probability of a first marriage being intact after 10 years is $0.68 .{ }^{17}$ The literature has also noted an "empty nest effect", i.e., an increase in the divorce risk when children leave the parental home. Hiedemann, Suhomlinova and O'Rand (1998) find that the empty nest effect increases the divorce hazard by 50 - 200 percent. Walker and Zhu (2004) find an effect at the lower end of this range for the UK. In our calibrated model, the divorce hazard is at its lowest when the kids are in their early teens, and we calibrate the model so that it generates an increase in the hazard of 75 percent from this point to two years after the termination of investments.

The most controversial stylized fact is the impact of divorce on kids' outcomes, represented in the model by the accumulated family capital. While there is a strong negative empirical association between divorce and children's outcomes, establishing the causal effect of divorce on kids outcomes has proven more difficult. Our reading of the literature is that the causal effects are overall limited in size, especially for kids who are older when the divorce occurs. ${ }^{18}$ This effectively puts a lower bound on $\lambda_{m}$. In order to capture this in our calibrated model, we compare the capital stock,

fraction of men who are in the labor force. Table A-6 from BLS ATUS statistics gives time spent in primary activities by mothers and fathers during the period 2009-2013 by gender and labour force status.

17. See Copen et al. (2012)

18. For example, see Gruber (2003), Piketty (2003), Björklund and Sundström (2006) and Francesconi et al. (2010). 

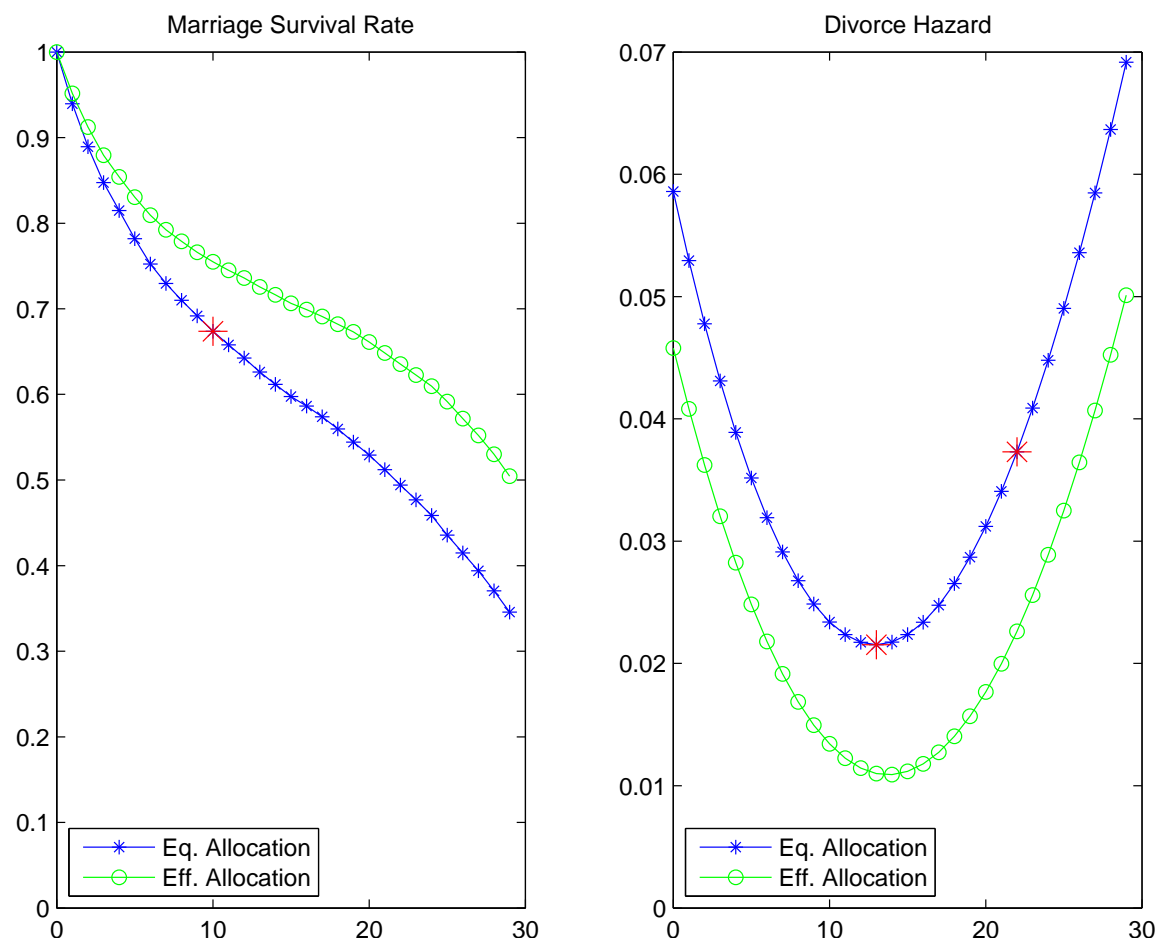

Figure 2. Marriage survival rate and divorce hazard by marriage duration

ten years post-divorce, for divorcing couples relative to couples who remain intact (by duration at divorce), and cap the negative effect of divorce at 15 percent. The final set of calibrated parameter values are shown in Table 1 . The top panel gives the parameter values imposed based on the literature. The middle panel gives the parameter values that were obtained by matching the model to the stylized facts listed in the bottom panel.

In Figure 2, we consider the impact of present bias on marital outcomes. The left panel shows the fraction of couples still married by years since marriage. In addition to the matched fraction at 10 years since marriage (highlighted with a red marker), the model also closely matches the median marriage duration of 20 years. The figure highlights that even a modest degree of present bias can lead to significant over-divorcing. For example, at durations between 10 and 30 years since marriage, the fraction of couples that have divorced in the laissez-faire allocation is 30-40 percent larger than in the efficient allocation. The extent of overdivorcing also becomes apparent in the right panel which shows the equilibrium divorce hazard by marriage duration. The divorce hazard is naturally U-shaped: it decreases as family capital is gradually accumulated, but then increases again due to the shortening of the remaining time horizon and the gradual depreciation of the capital stock. It is 
thus at its lowest when the kids are in their teens, and at this stage the divorce hazard under present-bias is about double the efficient hazard. ${ }^{19}$

In Figure 3, we present our results for the time allocation choices by females and males over their investment phase. The two top panels compare the laissez-faire equilibrium with the efficient allocation. In general, the effect of present bias on couples' time allocation choices is quantitatively smaller than its impact on divorce decisions. In particular, a present bias reduces both female and male household time by roughly 15-17 percent as compared to the first-best, with relatively little variation by marriage duration. The bottom panel shows how divorced couples devote less time to household production. In proportional terms, divorced couples, both men and women, tend to devote about 20 percent less time to household production relative to married couples.

In Figure 4, we focus our attention on how the stock of family-specific capital evolves with marriage duration. The left panel shows how the average capital stock in the present-biased equilibrium is lower than in the efficient allocation. Note that this is a combination of more couples being divorced and lower investments in each marital state. At any duration, the average capital stock accumulated by a presentbiased couple is about 11 percent below the average capital stock they would have had in the efficient allocation. The right panel illustrates the capital stock at 10 year post divorce for couples who divorce at time $t$ relative to the corresponding capital stock for couples who are still intact at $t+10$. Naturally the impact of divorce is larger the earlier it occurs. As noted above, we have calibrated the model so that this impact of divorce does not exceed 15 percent (highlighted by the red marker). Interestingly, present bias does not exacerbate the negative impact of divorce.

In Figure 5, we turn to the efficiency-restoring policy in the calibrated model. The left panel shows the optimal earnings tax for married and divorced couples by years since marriage. As noted above, $\hat{\tau}_{t}^{m}<\hat{\tau}_{t}^{d}$ and both are decreasing over time. In addition, both are quantitatively very close to $(1-\beta) \gamma \delta$ (highlighted by the horizontal red line). More interesting is the efficiency-restoring divorce tax shown in the right panel. This is inverted U-shaped and is largest during children's early teenage years, i.e., when the gap between the laissez-fair and the efficient divorce hazard is at its largest. In quantitative terms, the maximum optimal divorce tax of 0.095 corresponds to roughly 10 percent of the annual earnings of a married couple during their investment phase. In contrast, the optimal divorce tax for couples who are well past their investment phase is relatively minor.

19. The red markers highlight the increase in the divorce hazard from when the child is aged 13 to aged 22 which was match to 75 percent. 

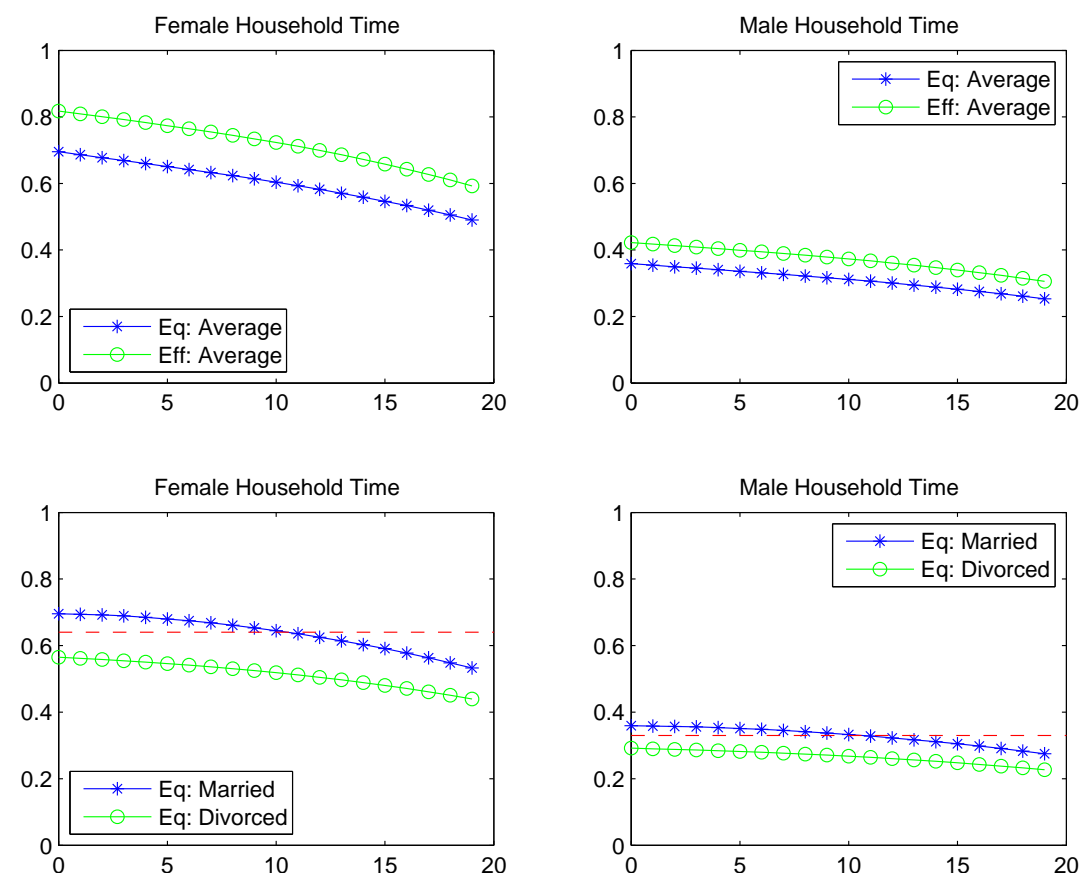

FIGURE 3. Fraction of time devoted to household production by marriage duration.
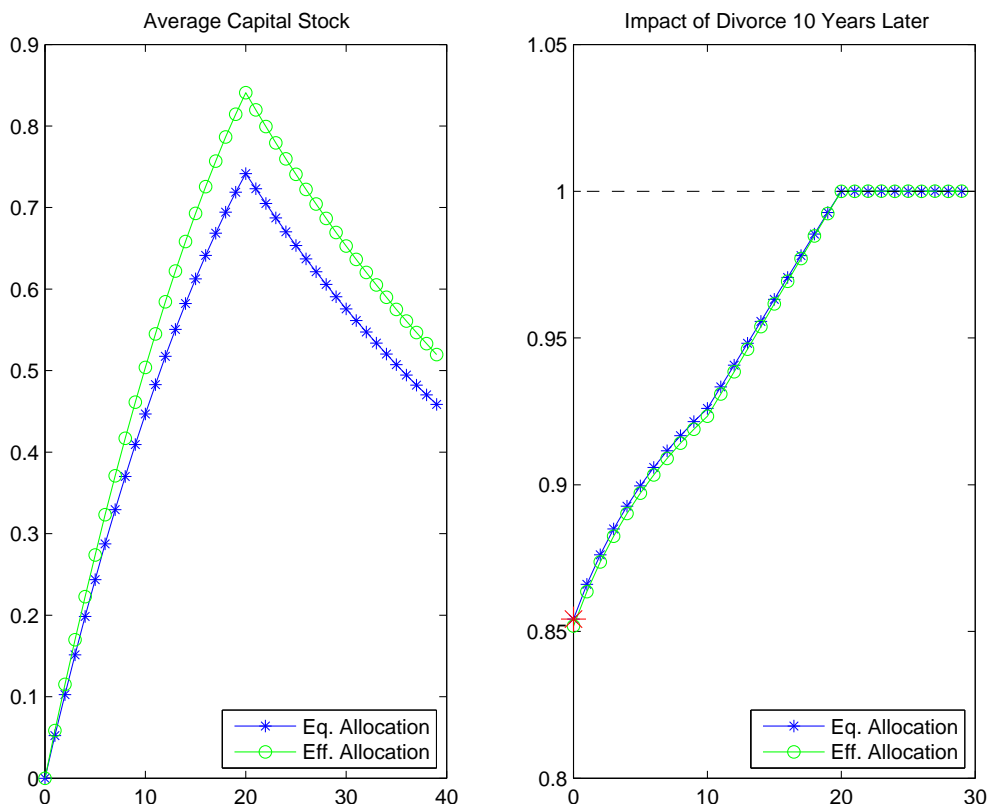

FIgURE 4. Average accumulated capital stock and impact of divorce on accumulated capital 10 years on by marriage duration 

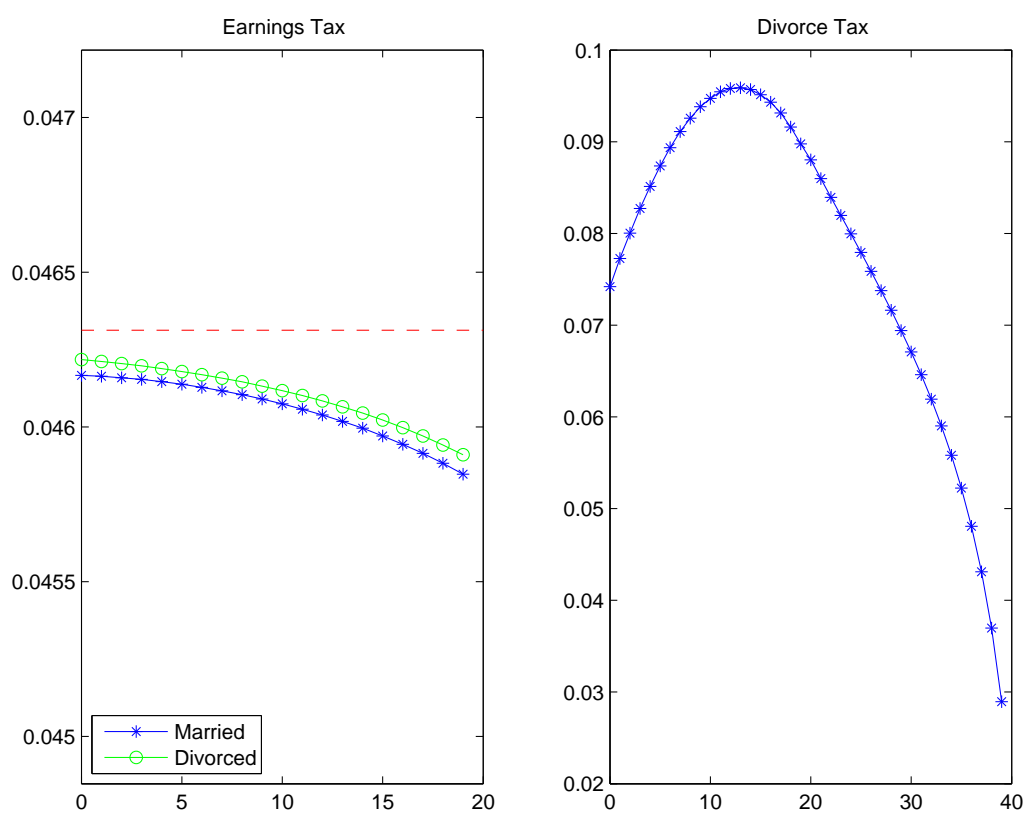

FIGURE 5. Efficiency-restoring earnings and divorce taxes by marriage duration.

\section{Concluding Remarks}

The dominant view among family economists is that the basic dynamics of household decision-making can be explained within a framework in which family members behave fully rationally over time. This paper departs from this view and takes some steps towards connecting the economic theory of the family with behavioral research on time-inconsistent preferences. At the center of our story are hyperbolic discounting couples who make two sets of decisions. First, they engage in home production activities, thereby accumulating family-specific capital over time. Second, the probability of divorce is endogenously determined by the level of accumulated family-specific capital itself. We show that present-biased preferences induce couples to underinvest in family-specific capital and to over-divorce. From a policy perspective, our model gives a sense of how earnings and divorce taxes that vary of the marital life cycle can completely undo the inefficiencies in the behavior of time-inconsistent couples. Moreover, it provides a rationale for the existence of marriage contracts that serve as barriers to hasty divorces.

We have presented the most parsimonious model we could construct in order to highlight our main ideas. Thus, our approach leaves open many interesting directions for future theoretical research. The model assumes that individuals do not consume leisure, nor does it allow couples to purchase market goods as substitutes for the their own time input into home production. It would be interesting to allow for either or both. We have also abstracted from decisions to enter marriage. Endogenizing 
marriage formation would add another margin likely to be affected by present-biased preferences.

In a similar vein, it would be worthwhile to consider a non-cooperative model of household behavior in our framework. The interesting and challenging aspect of this approach would be that it gives rise to a two-dimensional strategic decision problem: each individual would be playing a game against her own future self and against her marital partner. An additional level of complexity could be added by assuming that spouses have incomplete information regarding the degree of present bias of their partner.

Last but not least, while our contribution is a theoretical exercise, future work should attempt to assess the empirical relevance of present bias for intra-household decisions. In this regard, an interesting, albeit difficult, task would be to formulate an estimable model that allows inferences about the fractions of time-consistent and time-inconsistent households from observational data.

\section{References}

Alesina, A., Ichino, A. and L. Karabarbounis, "Gender-based taxation and the division of family chores," American Economic Journal: Economic Policy, 2011, 3(2), 1-40.

Andreoni, J. and C. Sprenger, "Estimating time preferences from convex budgets," American Economic Review, 2012, 102(7), 3333-3356.

Angeletos, G.M., Laibson, D., Repetto, A., Tobacman, J. and S. Weinberg, "The hyperbolic consumption model: calibration, simulation, and empirical evaluation," Journal of Economic Perspectives, 2001, 47-68.

Augenblick, N., Niederle, M. and C. Sprenger, "Working over time: dynamic inconsistency in real effort tasks," NBER Working Paper No. 18734, 2013.

Baker, L.A. and E. Emery, "When every relationship is above average: perceptions and expectations of divorce at the time of marriage," Law and Human Behavior, 1993, 17(4), 439-450.

Barham, V., Devlin, R.A. and J. Yang, "A theory of rational marriage and divorce," European Economic Review, 2009, 53, 93-106.

Bastani, S., Blomquist, S. and L. Micheletto, "The welfare gains of age-related optimal income taxation," International Economic Review, 2013, 54(4), 1219-1249.

Becker, G.S., "A theory of marriage: Part I," Journal of Political Economy, 1973, 81(4), 813-846.

Becker, G.S., "A theory of marriage: Part II," Journal of Political Economy, 1974, 82(2), S11-S26.

Becker, G.S., "A treatise of the family," Harvard University Press, Cambridge MA, 1981.

Becker, G.S., Landes, E.M. and R.T. Michael, "An economic analysis of marital instability," Journal of Political Economy, 1977, 85(6), 1141-1187. 
Björklund, A. and M. Sundström, "Parental separation and children's education attainment: a siblings analysis on swedish register data," Economica, 2006, 73, 605624.

Blenkhorn, L.E., "Islamic marriage contracts in american courts: interpreting mahr agreements as prenuptials and their effect on muslim women," Southern California Law Review, 2002, 76, 189-276.

Blomquist, S. and L. Micheletto, "Age-related optimal income taxation," The Scandinavian Journal of Economics, 2008, 110(1), 45-71.

Boskin M.J. and E. Sheshinski, "Optimal tax treatment of the family: married couples," Journal of Public Economics, 1983, 20, 281-297.

Bureau of Labor Statistics, "Women in the labor force: a databook," Report 1052, 2014.

Byrne, M.M. and P. Thompson, "Screening and preventable illness," Journal of Health Economics, 2001, 20(6), 1077-1088.

Carlsson, F. and X. Yang, "Intertemporal choice shifts in households: do they occur and are they good?," Working Papers in Economics No. 569, 2013.

Clark, S., "Law, property, and marital dissolution," Economic Journal, 1999, 109 (454), 41-54.

Copen, C.E., Daniels, K., Vespa, J. and W.D. Mosher, "First marriages in the United States: data from the 2006-2010 National Survey of family growth," National Health Statistics Reports No. 49, 2012.

Diamond, P. and B. Köszegi, "Quasi-hyperbolic discounting and retirement," Journal of Public Economics, 2003, 87(9), 1839-1872.

Fan, C.S., "A model of endogenous divorce and endogenous fertility," Journal of Population Economics, 2001, 14(1), 101-117.

Francesconi, M., Jenkins S.P. and T. Siedler, "Childhood family structure and schooling outcomes: evidence for Germany," Journal of Population Economics, 2010, 23(3), 1073-1103.

Francesconi, M. and A. Muthoo, "Control rights in complex partnerships," Journal of the European Economic Association, 2011, 9(3), 551-589.

Gruber, J., "Is making divorce easier bad for children? The long-run implications of unilateral divorce," Journal of Labor Economics, 2004, 22(4), 799-833.

Gruber, J. and B. Köszegi, "Tax incidence when individuals are time-inconsistent: the case of cigarette excise taxes," Journal of Public Economics, 2004, 88(9), 19591987.

Hardin, J.A.,, "Religious postmarital dispute resolution: jewish marriage contracts and civil courts," Journal on Dispute Resolution, 1988, 4(91), 97-106.

Hiedemann, B., Suhomlinova, O. and A.M. O'Rand, "Economic independence, economic status, and empty nest in midlife marital disruption," Journal of Marriage and Family, 1998, 60(1), 219-231.

Ikeda, S., Kang, M.I. and F. Ohtake, "Hyperbolic discounting, the sign effect, and the body mass index," Journal of Health Economics, 2010, 29(2), 268-284.

Immervoll, H., Kleven, H.J., Kreiner, C.T. and N. Verdelin, "Optimal tax and transfer programs for couples with extensive labor supply responses," Journal 
of Public Economics, 2011, 95(11-12), 1485-1500.

İmrohoroğlu, A., İmrohoroğlu, S. and D.H. Joines, "Time-inconsistent preferences and social security," The Quarterly Journal of Economics, 2003, 118(2), 745-784.

Jackson, M. and L. Yariv, "Collective dynamic choice: the necessity of time inconsistency," American Economic Journal: Microeconomics, 2015 7(4), 150-178.

Konrad, K., "Social security and strategic inter-vivos transfers of social capital," Journal of Population Economics, 1995, 8, 315-326.

Konrad, K. and K.E. Lommerud, "The bargaining family revisited," The Canadian Journal of Economics, 2000, 33(2), 471-487.

Laibson, D., "Golden eggs and hyperbolic discounting," Quarterly Journal of Economics, 1997, 62, 443-477.

Laibson, D., "Life-cycle consumption and hyperbolic discount functions," European Economic Review, 1998, 42(3), 861-871.

Lommerud, K.E., "Marital division of labor with risk of divorce: the role of "voice" enforcement of contracts," Journal of Labor Economics, 1989, 7(1), 113-127.

Lundberg, S. and R.A. Pollak, "Efficiency in marriage," Review of Economics of the Household, 2003, 1 (3), 153-167.

Malin, B.A., "Hyperbolic discounting and uniform savings floors," Journal of Public Economics, 2008, 92, 1986-2002.

Manuelli, R.E., Seshadri, A. and Y. Shin, "Lifetime Labor supply and human capital investment," Federal Reserve Bank of St. Louis Working Paper 2012-004A, 2012.

Mazzocco, M., "Household intertemporal behavior: a collective characterization and a test of commitment," Review of Economic Studies, 2007, 74(3), 857-895.

Meier, S. and, C. Sprenger, "Present-biased preferences and credit card borrowing," American Economic Journal: Applied Economics, 2010, 2(1), 193-210.

Meier, V. and, H. Rainer, "Pigou meets Ramsey: gender-based taxation with non-cooperative couples," European Economic Review, 2015, 77, 28-46.

OECD, Employment Outlook, 2008.

O'Donoghue, T. and M. Rabin, "Doing it now or later," The American Economic Review, 1999a, 89(1), 103-124.

O'Donoghue, T. and M. Rabin, "Incentives for procrastinators," Quarterly Journal of Economics, 1999b, 114(3), 769-816.

O'Donoghue, T. and M. Rabin, "Studying optimal paternalism, illustrated by a model of sin taxes," American Economic Review, 2003, 93(2), 186-191.

O'Donoghue, T. and M. Rabin, "Optimal sin taxes," Journal of Public Economics, 2006, 90(10), 1825-1849.

Piketty, T., "The impact of divorce on school performance: evidence from France, 1968-2002," CEPR Discussion Paper No. 4146, 2003.

Rainer, H., "Should we write prenuptial contracts?," European Economic Review, 2007, 51(2), 337-363.

Prescott, E.C., "Theory ahead of business cycle measurement," Carnegie-Rochester Conference Series on Public Policy, 1986, 25, 11-44. 
Rasul, I., "The economics of child custody," Economica, 2006, 73, 1-25.

Schwarz, M.E. and E. Sheshinski, "Quasi-hyperbolic discounting and social security systems," European Economic Review, 2007, 51(5), 1247-1262.

Spaht, K.S., "Louisiana's covenant marriage: social analysis and legal implications," Louisiana Law Review, 1998, 59, 63-130.

Thaler, R.H. and S. Benartzi, "Save more tomorrow: using behavioral economics to increase employee saving," Journal of Political Economy, 2004, 112(1), 164-187.

Waite, L.J., Browning, D.,Doherty, W.J., Gallagher M. and S.M. Stanley, "Does divorce make people happy? Findings from a study of unhappy marriages," New York: Institute for American Values, 2002.

Walker, I. and Y. Zhu, "Child support liability and partnership dissolution," Institute for Fiscal Studies Working Papers, 2004.

Weinzierl, M., "The surprising power of age-dependent taxes," The Review of Economic Studies, 2011, 78(4), 1490-1418.

Weiss, Y. and R.J. Willis, "Children as collective goods and divorce settlements," Journal of Labor Economics, 1985, 268-292.

Weiss, Y. and R.J. Willis, "Match quality, new information, and marital dissolution," Journal of Labor Economics, 1997, 15(1), 293-329. 


\section{Online Appendix: Not for Publication}

Proof of Lemma 1. While married, a couple choose their time allocation cooperatively. A consequence of this is that, whatever level of total household production they choose, their associated time allocation will minimize the cost in terms of foregone earnings. Thus consider the cost minimization problem

$$
C(v) \equiv \min _{g_{s}, g_{h}}\left\{\sum_{i} \omega_{i} g_{i} \mid v\left(g_{s}, g_{h}\right) \geq v\right\},
$$

where $v$ is the total level of household production. The solution of this problem has standard properties: the marginal rate of technical substitution is set equal to the wage ratio, $\omega_{s} / \omega_{h}=v_{s}\left(g_{s}, g_{h}\right) / v_{h}\left(g_{s}, g_{h}\right)$, and the marginal cost satisfies

$$
C^{\prime}(v)=\frac{\omega_{s}}{v_{s}\left(g_{s}, g_{h}\right)}=\frac{\omega_{h}}{v_{h}\left(g_{s}, g_{h}\right)} .
$$

Strict concavity of $v(\cdot)$ implies a strictly increasing marginal cost, $C^{\prime \prime}(\cdot)>0$.

Consider now the household production problem at $t=2$ for a couple that chose to remain married. Using the cost function, we can focus on the chosen level of production level, denoted $\hat{v}_{2}^{m}$, which maximizes the couple's joint objective function,

$$
\max _{v_{2}^{m}}\left\{2 \theta+(1+\beta \delta)\left[\sum_{i} \omega_{i}+2\left(G_{1}^{m}+v_{2}^{m}\right)\right]-C\left(v_{2}^{m}\right)\right\}
$$

and hence satisfies the first order condition,

$$
2(1+\beta \delta)-C^{\prime}\left(\hat{v}_{2}^{m}\right)=0
$$

while the second order condition $-C^{\prime \prime}\left(v_{2}^{m}\right)<0$ is satisfied due to convexity of the cost function. The first order conditions (11) follow from (A4) and (A2).

After a divorce, the couple no longer choose their time allocation cooperatively. However, the assumption on $\lambda_{i}$ in (8) implies that the couple's chosen time allocation continue to minimize the total cost of their chosen level of production, $\hat{v}_{2}^{d}$ : the individual first order conditions in (13), along with (A2), implies that $\hat{v}_{2}^{d}$ satisfies

$$
\Lambda(1+\beta \delta)-C^{\prime}\left(\hat{v}_{2}^{d}\right)=0
$$

which, together with (A2) and (8), gives the first order condition in (13).

Comparing eqs. (A4) and (A5), and using that $C(\cdot)$ is strictly convex it is clear that $\hat{v}_{2}^{d}<\hat{v}_{2}^{m}$ as $\Lambda<2$. From the cost minimization problem in (A1), it then also follows that a couple forego more earnings if still married than if divorced.

Proof of Lemma 2. As the couple is married at $t=1$, they choose their time allocation cooperatively, thus minimizing the cost of production for their chosen level 
of household production. Their joint objective function $V_{1}=V_{s 1}+V_{h 1}$ can then be written as a choice of $G_{1}^{m}$,

$$
\begin{aligned}
V_{1}= & \sum_{i} \omega_{i}+2 G_{1}^{m}-C\left(G_{1}^{m}\right) \\
& +\beta \delta\left\{(1-F(\hat{\theta}))\left[(1+\delta)\left[\sum_{i} \omega_{i}+2 \hat{G}_{2}^{m}\right]-C\left(\hat{v}_{2}^{m}\right)\right]\right. \\
& \left.+2 \int_{\hat{\theta}}^{\infty} \theta f(\theta) \mathrm{d} \theta+F(\hat{\theta})\left[(1+\delta)\left[\sum_{i} \omega_{i}+\Lambda \hat{G}_{2}^{d}\right]-C\left(\hat{v}_{2}^{d}\right)\right]\right\},
\end{aligned}
$$

where $\hat{\theta}=\hat{\theta}\left(G_{1}^{m}\right)$ and $\hat{G}_{2}^{k}=G_{1}^{m}+\hat{v}_{2}^{k}$ with $G_{1}^{m}=v\left(g_{s 1}^{m}, g_{h 1}^{m}\right)$. The first order condition characterizing $\hat{G}_{1}^{m}$ thus becomes

$$
\begin{aligned}
C^{\prime}\left(\hat{G}_{1}^{m}\right)= & +\beta \delta(1+\delta)\{2-(2-\Lambda) F(\hat{\theta})\} \\
& +2 \beta \delta f(\hat{\theta}) \hat{\theta}^{\prime}\left\{\frac{\hat{\mathcal{C}}_{2}}{2}-(1+\delta)\left[\hat{G}_{2}^{m}-\frac{\Lambda}{2} \hat{G}_{2}^{d}\right]-\hat{\theta}\right\}
\end{aligned}
$$

We can now substitute for $\hat{\theta}$ and $\hat{\theta}^{\prime}$ using eqs. (16)-(17) and simplify the right hand side. This gives

$$
C^{\prime}\left(\hat{G}_{1}^{m}\right)=2+\beta \delta(1+\delta)\left\{2-(2-\Lambda)\left[F\left(\hat{\theta}\left(\hat{v}_{1}^{m}\right)\right)-\chi f\left(\hat{\theta}\left(\hat{G}_{1}^{m}\right)\right)\right]\right\}
$$

with $\chi$ defined as in (21). The result then follows immediately from (A2).

Proof of Proposition 1. Part (a) follows immediately from (A4) and (A5) which show that a lower $\beta$ implies a lower $C^{\prime}\left(\hat{v}_{2}^{k}\right)$ and hence a lower level of household production $\hat{v}_{2}^{k}$ in each marital state $k$. Thus, more present bias causes a couple to reduce the level of total household production at $t=2$ in both marital states.

To establish part (b), note that, in terms of total household production levels, the divorce threshold characterized in (16) can be rewritten as

$$
\hat{\theta}=\frac{C\left(\hat{v}_{2}^{m}\right)-C\left(\hat{v}_{2}^{d}\right)}{2}-(1+\beta \delta)\left[\left(G_{1}^{m}+\hat{v}_{2}^{m}\right)-\frac{\Lambda}{2}\left(G_{1}^{m}+\hat{v}_{2}^{d}\right)\right] .
$$

Differentiating we obtain

$$
\begin{aligned}
\frac{\partial \hat{\theta}}{\partial \beta}= & {\left[(1+\beta \delta) \frac{\Lambda}{2}-\frac{C^{\prime}\left(\hat{v}_{2}^{d}\right)}{2}\right] \frac{\partial \hat{v}_{2}^{d}}{\partial \beta}-\left[(1+\beta \delta)-\frac{C^{\prime}\left(\hat{v}_{2}^{m}\right)}{2}\right] \frac{\partial \hat{v}_{2}^{m}}{\partial \beta} } \\
& -\delta\left[\left(G_{1}^{m}+\hat{v}_{2}^{m}\right)-\frac{\Lambda}{2}\left(G_{1}^{m}+\hat{v}_{2}^{d}\right)\right] .
\end{aligned}
$$


The first two terms vanish due to eqs. (A4) and (A5), leaving

$$
\frac{\partial \hat{\theta}}{\partial \beta}=-\delta\left[\left(G_{1}^{m}+\hat{v}_{2}^{m}\right)-\frac{\Lambda}{2}\left(G_{1}^{m}+\hat{v}_{2}^{d}\right)\right]<0
$$

where the sign follows from the facts that $\hat{v}_{2}^{m}>\hat{v}_{2}^{d}$ (see Lemma 1) and $\Lambda<2$. Next note that $\hat{\theta}\left(G_{1}^{m}\right)$ converges to $\tilde{\theta}\left(G_{1}^{m}\right)$ as $\beta$ approaches unity. Since $\hat{\theta}$ additionally decreases with $\beta$, any reduction in $\beta$ away from unity raises the divorce threshold $\hat{\theta}\left(G_{1}^{m}\right)$ above $\tilde{\theta}\left(G_{1}^{m}\right)$. Present-biased couples therefore divorce for a larger set of match quality realizations than in the first-best solution.

Proof of Proposition 2. As noted in proof of Lemma 2 the first order condition characterizing the couple's choice of first period level of household production satisfies, $C^{\prime}\left(\hat{v}_{1}^{m}\right)=\mathcal{B}\left(\hat{v}_{1}^{m}\right)$, where the marginal benefit $\mathcal{B}\left(\hat{v}_{1}^{m}\right)$ is given by the right hand side of (A8), and with $\chi$ defined as in (21). The cost function on the left hand side does not depend on $\beta$ but the marginal benefit does. Hence we now characterize the impact of $\beta$ on $\mathcal{B}$ for a given value of $v_{1}^{m}$, noting that this impact can both be direct (in terms of $\beta$ appearing directly in $\mathcal{B}$ ) or via future choices. For notational convenience, we suppress the arguments of $\hat{\theta}$. We then obtain that

$$
\begin{aligned}
\frac{\partial \mathcal{B}}{\partial \beta}= & \delta(1+\delta)\{[2-(2-\Lambda)(F(\hat{\theta})-\chi f(\hat{\theta}))] \\
& \left.-\beta(2-\Lambda)\left[f(\hat{\theta}) \frac{\partial \hat{\theta}}{\partial \beta}-\left(f(\hat{\theta}) \frac{\partial \chi}{\partial \beta}+\chi f^{\prime}(\hat{\theta}) \frac{\partial \hat{\theta}}{\partial \beta}\right)\right]\right\} .
\end{aligned}
$$

We focus on evaluating this expression in the limit where $\beta \rightarrow 1$. This allows us to consider how the introduction of present bias - i.e, a marginal reduction in $\beta$ away from unity - affects $\mathcal{B}$. We first note from eq. (21) that $\chi=0$ in the limit where $\beta \rightarrow 1$. Moreover, from eqs. (A11) and (21) it follows that

$$
\left.\frac{\partial \hat{\theta}}{\partial \beta}\right|_{\beta \rightarrow 1}=\left.\frac{\partial \chi}{\partial \beta}\right|_{\beta \rightarrow 1}=-\delta\left[\left(G_{1}^{m}+\hat{v}_{2}^{m}\right)-\frac{\Lambda}{2}\left(G_{1}^{m}+\hat{v}_{2}^{d}\right)\right]<0 .
$$

It now follows immediately that,

$$
\left.\frac{\partial \mathcal{B}}{\partial \beta}\right|_{\beta \rightarrow 1}=\delta(1+\delta)[2-(2-\Lambda) F(\hat{\theta})]>0
$$

Thus, a decrease in $\beta$ from unity -i.e., the introduction of present bias in couples' preferences - reduces the marginal benefits from first-period household production. Given the convexity of the cost function $C$, it thus follows that a couple that are (marginally) present biased will choose a level of household production that is below the first best level. 
Proof of Corollary 1. Suppose that the total private gains from marriage are drawn from a uniform probability density function: $\theta \sim \mathcal{U}(\underline{\theta}, \bar{\theta})$. Under this assumption,

$$
F(\hat{\theta})=\frac{\hat{\theta}-\underline{\theta}}{\bar{\theta}-\underline{\theta}}, \quad \text { and } \quad \chi f(\hat{\theta})=\frac{\chi}{\bar{\theta}-\underline{\theta}} .
$$

Subtracting and using (21) we obtain

$$
F(\hat{\theta})-\chi f(\hat{\theta})=\frac{\hat{\hat{\theta}}-\underline{\theta}}{\bar{\theta}-\underline{\theta}}
$$

where

$$
\hat{\hat{\theta}} \equiv \frac{C\left(\hat{v}_{2}^{m}\right)-C\left(\hat{v}_{2}^{d}\right)}{2}-(1+\beta \delta)\left(\frac{1+\delta(2-\beta)}{1+\delta}\right)\left[\left(v_{1}^{m}+\hat{v}_{2}^{m}\right)-\frac{\Lambda}{2}\left(v_{1}^{m}+\hat{v}_{2}^{d}\right)\right] .
$$

The first-order condition characterizing $v_{1}^{m}$ is as before $C^{\prime}\left(v_{1}^{m}\right)=\mathcal{B}\left(\hat{v}_{1}^{m}\right)$, where the marginal benefit can now be written as

$$
\mathcal{B}\left(\hat{v}_{1}^{m}\right)=2+\beta \delta(1+\delta)\left[2-(2-\Lambda)\left(\frac{\hat{\hat{\theta}}-\underline{\theta}}{\bar{\theta}-\underline{\theta}}\right)\right] .
$$

Differentiating $\mathcal{B}$ with respect to $\beta$ we obtain

$$
\frac{\partial \mathcal{B}}{\partial \beta}=\delta(1+\delta)\left[2-(2-\Lambda)\left(\frac{\hat{\hat{\theta}}-\underline{\theta}}{\overline{\bar{\theta}}-\underline{\theta}}\right)\right]-\beta \delta(1+\delta)\left(\frac{2-\Lambda}{\bar{\theta}-\underline{\theta}}\right) \frac{\partial \hat{\hat{\theta}}}{\partial \beta} .
$$

To establish the result, we need to show that $\partial \mathcal{B} / \partial \beta>0$ for any $\beta \in(0,1)$ (and for any given value of $\left.v_{1}^{m}\right)$. The first term on the r.h.s. of (A19) is positive. Thus, a sufficient condition for $\partial \mathcal{B} / \partial \beta>0$ is that $\partial \hat{\hat{\theta}} / \partial \beta<0$. Differentiating eq. (A17) with respect to $\beta$ we obtain,

$$
\begin{aligned}
\frac{\partial \hat{\hat{\theta}}}{\partial \beta}= & {\left[\frac{C^{\prime}\left(\hat{v}_{2}^{m}\right)}{2}-\psi(1+\beta \delta)\right] \frac{\partial \hat{v}_{2}^{m}}{\partial \beta}-\left[\frac{C^{\prime}\left(\hat{v}_{2}^{d}\right)}{2}-\psi(1+\beta \delta) \frac{\Lambda}{2}\right] \frac{\partial \hat{v}_{2}^{d}}{\partial \beta} } \\
& -\frac{2 \delta^{2}(1-\beta)}{1+\delta}\left[\left(v_{1}^{m}+\hat{v}_{2}^{m}\right)-\frac{\Lambda}{2}\left(v_{1}^{m}+\hat{v}_{2}^{d}\right)\right],
\end{aligned}
$$

where we define $\psi \equiv(1+\delta(2-\beta)) /(1+\delta)>1$. We can substitute for the marginal cost using eqs. (A4) and (A5) and also use that these same equations imply that

$$
\frac{\partial \hat{v}_{2}^{m}}{\partial \beta}=\frac{2 \delta}{C^{\prime \prime}\left(\hat{v}_{2}^{m}\right)} \quad \text { and } \quad \frac{\partial \hat{v}_{2}^{d}}{\partial \beta}=\frac{\Lambda \delta}{C^{\prime \prime}\left(\hat{v}_{2}^{d}\right)},
$$


We further restrict our attention to production functions giving rise to a cost function satisfying $C^{\prime \prime \prime} \leqslant 0 .{ }^{20}$ Thus,

$$
\begin{aligned}
\frac{\partial \hat{\hat{\theta}}}{\partial \beta}= & -\frac{(1+\beta \delta)(\psi-1) \delta}{2}\left[\frac{4}{C^{\prime \prime}\left(\hat{v}_{2}^{m}\right)}-\frac{\Lambda^{2}}{C^{\prime \prime}\left(\hat{v}_{2}^{d}\right)}\right] \\
& -\frac{2 \delta^{2}(1-\beta)}{1+\delta}\left[\left(v_{1}^{m}+\hat{v}_{2}^{m}\right)-\frac{\Lambda}{2}\left(v_{1}^{m}+\hat{v}_{2}^{d}\right)\right]<0,
\end{aligned}
$$

where the sign follows from the facts that $\hat{v}_{2}^{m}>\hat{v}_{2}^{d}$ (See Lemma 1) and $2>\Lambda$. Thus, if $\theta$ is drawn from a uniform probability density function, the couple will underproduce family-specific capital for any degree of present bias.

Proof of Proposition 3. From the perspective of period zero, and for a given divorce cost $\zeta$, the couple's joint intertemporal utility, $V_{0}=V_{0 s}+V_{0 h}$, can be written as

$$
\begin{aligned}
\frac{V_{0}}{\beta \delta}= & \sum_{i} \omega_{i}+2 \hat{v}_{1}^{m}-C\left(\hat{v}_{1}^{m}\right)+2 \delta \int_{\hat{\theta}\left(\zeta, \hat{v}_{1}^{m}(\zeta)\right)}^{\infty} \theta f(\theta) \mathrm{d} \theta \\
& +\delta[1-F(\hat{\theta})]\left\{(1+\delta)\left[\sum_{i} \omega_{i}+2\left(\hat{v}_{1}^{m}+\hat{v}_{2}^{m}\right)\right]-C\left(\hat{v}_{2}^{m}\right)\right\} \\
& +\delta F(\hat{\theta})\left\{(1+\delta)\left[\sum_{i} \omega_{i}+\Lambda\left(\hat{v}_{1}^{m}+\hat{v}_{2}^{d}\right)\right]-\zeta-C\left(\hat{v}_{2}^{d}\right)\right\}
\end{aligned}
$$

where the divorce threshold that the couple expect themselves to adopt at $t=2$ can now be written as

$$
\hat{\theta}=\frac{\hat{\mathcal{C}}_{2}-\zeta}{2}-(1+\beta \delta)\left[\left(\hat{v}_{1}^{m}+\hat{v}_{2}^{m}\right)-\frac{\Lambda}{2}\left(\hat{v}_{1}^{m}+\hat{v}_{2}^{d}\right)\right] .
$$

Note that we used that the marital status-specific time allocations at $t=2$ do not depend on $\zeta$ (see 11 and 13), whereas that at $t=1$ does: $\partial \hat{v}_{1}^{m} /\left.\partial \zeta\right|_{\zeta=0}$ is generally nonzero. Indeed we will show below that it is strictly positive for the case of uniformly distributed match quality shocks. Note also that $\zeta$ affects the divorce threshold both directly and also indirectly via $\hat{v}_{1}^{m}$. As we will consider the incentives to introduce a divorce cost - that is, to increase $\zeta$ from zero - the couple's behaviour will be evaluated at $\zeta=0$, thus corresponding to the laissez-faire equilibrium described above.

20. Many commonly used production function yield cost functions that satisfy having $C^{\prime \prime \prime} \leq 0$. Examples include the Cobb-Douglas functions $v\left(x_{1}, x_{2}\right)=x_{1}^{\alpha_{1}} x_{2}^{\alpha_{2}}$ with $\frac{1}{2} \leqslant \alpha_{1}+\alpha_{2}<1$ or the independent production functions $v\left(x_{1}, x_{2}\right)=x_{1}^{\alpha}+x_{2}^{\alpha}$ with $\frac{1}{2} \leqslant \alpha<1$. 
Differentiating (A23), evaluating at $\zeta=0$, and collecting terms gives that

$$
\begin{aligned}
\frac{\partial V_{0} /\left.\partial \zeta\right|_{\zeta=0}}{\beta \delta}= & \left.\left(2-C^{\prime}\left(\hat{v}_{1}^{m}\right)\right) \frac{\partial \hat{v}_{1}^{m}}{\partial \zeta}\right|_{\zeta=0} \\
& +2 \delta f(\hat{\theta})\left\{\frac{\hat{\mathcal{C}}_{2}}{2}-(1+\delta)\left[\hat{G}_{2}^{m}-\frac{\Lambda}{2} \hat{G}_{2}^{d}\right]-\hat{\theta}\right\}\left[\frac{\partial \hat{\theta}}{\partial \zeta}+\frac{\partial \hat{\theta}}{\partial \hat{v}_{1}^{m}} \frac{\partial \hat{v}_{1}^{m}}{\partial \zeta}\right]_{\zeta=0} \\
& +\left.\delta(1+\delta)\{2-F(\hat{\theta})(2-\Lambda)\} \frac{\partial \hat{v}_{1}^{m}}{\partial \zeta}\right|_{\zeta=0}-\delta F(\hat{\theta})
\end{aligned}
$$

where $\left[\frac{\partial \hat{\theta}}{\partial \zeta}+\frac{\partial \hat{\theta}}{\partial \hat{v}_{1}^{m}} \frac{\partial \hat{v}_{1}^{m}}{\partial \zeta}\right]_{\zeta=0}$ is the total - direct plus indirect - effect of $\zeta$ on $\hat{\theta}$, evaluated at $\zeta=0$. Note that, from (A24),

$$
\frac{\partial \hat{\theta}}{\partial \hat{v}_{1}^{m}}=-\frac{(1+\beta \delta)}{2}(2-\Lambda) \text { and } \quad \frac{\partial \hat{\theta}}{\partial \zeta}=-\frac{1}{2} .
$$

Using this, and also substituting for $\hat{\theta}$ using (A24) evaluated at $\zeta=0$, and using also the definition of $\chi$ in $(21)$ gives

$$
\begin{aligned}
\frac{\partial V_{0} /\left.\partial \zeta\right|_{\zeta=0}}{\beta \delta}= & {\left.\left[2-C^{\prime}\left(\hat{v}_{1}^{m}\right)+\delta(1+\delta)\{2-(2-\Lambda)[F(\hat{\theta})-f(\hat{\theta}) \chi]\}\right] \frac{\partial \hat{v}_{1}^{m}}{\partial \zeta}\right|_{\zeta=0} } \\
& -\delta\left\{F(\hat{\theta})-\delta(1-\beta) f(\hat{\theta})\left[\hat{G}_{2}^{m}-\frac{\Lambda}{2} \hat{G}_{2}^{d}\right]\right\} .
\end{aligned}
$$

Using then the characterization of the laissez-faire choice of first period investment in (A8) to substitute for $2-C^{\prime}\left(\hat{v}_{1}^{m}\right)$ and also using the definition of $\chi$ to substitute in the second term gives

$$
\begin{aligned}
\frac{\partial V_{0} /\left.\partial \zeta\right|_{\zeta=0}}{\beta \delta^{2}}= & \left.\{2-(2-\Lambda)[F(\hat{\theta})-f(\hat{\theta}) \chi]\}(1-\beta)(1+\delta) \frac{\partial \hat{v}_{1}^{m}}{\partial \zeta}\right|_{\zeta=0} \\
& -\left[F(\hat{\theta})-\frac{(1+\delta)}{(1+\beta \delta)} f(\hat{\theta}) \chi\right] .
\end{aligned}
$$

Note that, in the limit where $\beta \rightarrow 1, \partial V_{0} /\left.\partial \zeta\right|_{\zeta=0}=-\beta \delta^{2} F(\hat{\theta})<0$ (recall that $\chi$ limits to zero as well), implying that if the couple's present bias is sufficiently small, then they will not benefit from a contracted divorce cost. But for inframarginal degress of present bias, $\partial V_{0} /\left.\partial \zeta\right|_{\zeta=0}>0$ if and only if the right hand side of (A28) is positive. Solving for $F(\hat{\theta})$, this is equivalent to the stated condition.

We can next readily confirm that $\hat{v}_{1}^{m}$ is increasing in $\zeta$ under the assumption of uniformly distributed match quality shocks, $\theta \sim \mathcal{U}(\underline{\theta}, \bar{\theta})$. With a divorce cost $\zeta>0$, the first order condition characterizing $\hat{v}_{1}^{m}(\zeta)$ can be written as before as 
$C^{\prime}\left(\hat{v}_{1}^{m}(\zeta)\right)=\mathcal{B}$, but where the marginal benefit can now be written as

$$
\begin{aligned}
\mathcal{B}= & +\beta \delta(1+\delta)[2-(2-\Lambda) F(\hat{\theta})] \\
& +2 \beta \delta f(\hat{\theta})\left\{\frac{\hat{\mathcal{C}}_{2}}{2}-(1+\delta)\left[\hat{G}_{2}^{m}+\frac{\Lambda}{2} \hat{G}_{2}^{d}\right]-\frac{\zeta}{2}-\hat{\theta}\right\} \frac{\partial \hat{\theta}}{\hat{v}_{1}^{m}}
\end{aligned}
$$

where $\hat{G}_{2}^{k}=\hat{v}_{1}^{m}(\zeta)+\hat{v}_{2}^{k}$. Consider now the direct effect of $\zeta$ on the marginal benefit $\mathcal{B}$, noting that part of this direct effect is the direct effect on $\hat{\theta}$. In doing we invoke the uniformity assumption which implies that $f(\theta)=f=1 /(\bar{\theta}-\underline{\theta})$ is constant, and we further note that $\partial \hat{\theta} / \partial \hat{v}_{1}^{m}$ is unaffected by $\zeta$ (see eq. A26). Thus we obtain

$$
\frac{\partial \mathcal{B}}{\partial \zeta}=-\beta \delta(1+\delta)(2-\Lambda) f \frac{\partial \hat{\theta}}{\partial \zeta}-2 \beta \delta f \frac{1}{2} \frac{\partial \hat{\theta}}{\hat{v}_{1}^{m}}-2 \beta \delta f \frac{\partial \hat{\theta}}{\partial \zeta} \frac{\partial \hat{\theta}}{\hat{v}_{1}^{m}}
$$

Invoking (A26) the last two terms cancel and we obtain that $\partial \mathcal{B} / \partial \zeta=$ $\beta \delta(1+\delta) f(1-\Lambda / 2)>0$. Since $\zeta$ raises the marginal benefit to $\hat{v}_{1}^{m}$ it follows that, under uniform match quality shocks, $\partial \hat{v}_{1}^{m} / \partial \zeta>0$.

Proof of Proposition 4. Consider first the couple's time allocation choice in the second period, starting with a couple that remain married. With a proportional tax $\tau_{2}$ on earnings, the time allocation choice that maximizes their joint intertemporal utility satisfies

$$
\frac{\omega_{i}\left(1-\tau_{2}\right)}{v_{i}\left(g_{s 2}^{m}, g_{h 2}^{m}\right)}=2(1+\beta \delta) .
$$

Contrasting this to the characterization of the first best time allocation in (23), we see that the efficiency-restoring tax, denoted $\hat{\tau}_{2}$, satisfies

$$
\frac{2(1+\beta \delta)}{\left(1-\hat{\tau}_{2}\right)}=2(1+\delta)
$$

Solving for $\hat{\tau}_{2}$ gives (28).

In contrast, after a divorce each spouse chooses his or her own time allocation to maximize the own intertemporal utility. However, as before the assumption in (8) implies that their choices also maximize the joint utility. Hence the time allocation choices of a divorced couple satisfies

$$
\frac{\omega_{i}\left(1-\tau_{2}\right)}{v_{i}\left(g_{s 2}^{m}, g_{h 2}^{m}\right)}=\Lambda(1+\beta \delta)
$$

Contrasting this to the characterization of the first best time allocation in (23), we see that $\hat{\tau}_{2}$ as defined in (28) restores efficiency of the time allocation also among divorced couples. With $\hat{\tau}_{2}$ set as in (28), it thus follows that $\hat{g}_{i 2}^{m}=\tilde{g}_{i 2}^{m}$ and $\hat{g}_{i 2}^{d}=\tilde{g}_{i 2}^{d}$. 
Turning next to the divorce decision, the match quality threshold adopted by couples under the policy is given by

$$
\hat{\theta}=\frac{\left(1-\hat{\tau}_{2}\right) \tilde{\mathcal{C}}_{2}-\eta}{2}-(1+\beta \delta)\left[\left(G_{1}^{m}+\tilde{v}_{2}^{m}\right)-\frac{\Lambda}{2}\left(G_{1}^{m}+\tilde{v}_{2}^{d}\right)\right]
$$

where we used that $\hat{\tau}_{2}$ induces the first best time allocation in each marital state (and that the lump-sum policy element $\alpha_{2}$ does not affect the divorce decision). Setting this theshold equal to the first best threshold in (24) as solving for the efficiency-restoring tax $\hat{\eta}$ gives

$$
\hat{\eta}=\delta(1-\beta)\left[2\left(G_{1}^{m}+\tilde{v}_{2}^{m}\right)-\Lambda\left(G_{1}^{m}+\tilde{v}_{2}^{d}\right)-\frac{1}{1+\delta} \tilde{\mathcal{C}}_{2}\right],
$$

where we also made use of the expression for $\hat{\tau}_{2}$ in (28). Note that, unlike $\hat{\tau}_{2}, \hat{\eta}$ generally depends on the capital stock carried forward from the first period, $G_{1}^{m}$. The first period policy will induce the couple to choose $G_{1}^{m}=\tilde{G}_{1}^{m}$; evaluating $\hat{\eta}$ at this first period choice, gives the expression for $\hat{\eta}$ in (28).

The lump-sum transfer given to the couple at the outset of the second period is the expected earnings tax revenue within the period plus the expected divorce fee:

$$
\hat{\alpha}_{2}=\hat{\tau}_{2}\left[(1-F(\tilde{\theta})) \sum_{i}\left[\omega_{i}\left(1-\tilde{g}_{i 2}^{m}\right)\right]+F(\tilde{\theta}) \sum_{i}\left[\omega_{i}\left(1-\tilde{g}_{i 2}^{d}\right)\right]\right]+F(\tilde{\theta}) \hat{\eta}
$$

Consider now the behavior of couples in the first period under policy, and with the second period policy set as outlined above. The couple's joint intertemporal utility can then be written as

$$
\begin{aligned}
V_{1}= & \sum_{i} \omega_{i}\left(1-\tau_{1}\right)\left(1-g_{i 1}^{m}\right)+\alpha_{1}+v\left(g_{s 1}^{m}, g_{h 1}^{m}\right) \\
& +\beta \delta\left\{\hat{\alpha}_{2}+(1-F(\tilde{\theta}))\left[\sum_{i} \omega_{i}\left[\left(1-\hat{\tau}_{2}\right)\left(1-\tilde{g}_{i 2}^{m}\right)+\delta\right]+(1+\delta) 2 \tilde{G}_{2}^{m}\right] \quad(\mathrm{A} 37)\right. \\
& \left.+F(\tilde{\theta})\left[\sum_{i} \omega_{i}\left[\left(1-\hat{\tau}_{2}\right)\left(1-\tilde{g}_{i 2}^{d}\right)+\delta\right]-\hat{\eta}+(1+\delta) \Lambda \tilde{G}_{2}^{d}\right]+2 \int_{\tilde{\theta}}^{\infty} \theta f(\theta) \mathrm{d} \theta\right\} .
\end{aligned}
$$

where we used that the second period policy induces first best behaviour. Substituting in $\hat{\tau}_{2}, \hat{\eta}$ and $\hat{\alpha}_{2}$, the first-order condition satisfied by the couple's first period effort choice reduces to

$$
\frac{\left(1-\tau_{1}\right) \omega_{i}}{v_{i}\left(\hat{g}_{s 1}^{m}, \hat{g}_{h 1}^{m}\right)}=2+\beta \delta(1+\delta)[2-(2-\Lambda) F(\tilde{\theta})] .
$$

Using the first-order condition for the first-best solution [eq. (25)], the efficiencyrestoring first-period earnings tax rate satisfies

$$
\frac{2+\beta \delta(1+\delta)[2-(2-\Lambda) F(\tilde{\theta})]}{1-\hat{\tau}_{1}}=2+\delta(1+\delta)[2-(2-\Lambda) F(\tilde{\theta})] .
$$


Solving for $\hat{\tau}_{1}$ gives the expression in (30). The first period lump sum transfer $\hat{\alpha}_{1}$ finally is simply the first period earnings by the couply given that tax rate $\hat{\tau}_{1}$ and the fact that they, under the policy, chooses the efficient first period time allocation.

Proof of Proposition 5. It is straightforward to establish part (1). In the first period, a naive couple believe that they will make their divorce and time allocation decisions at $t=2$ in a dynamically consistent way, i.e., that they will discount the third-period benefits of family-specific investments by $\delta$. Thus, a naive couple expect that their second-period choices, conditional on any chosen $G_{1}^{m}$, will correspond to the first-best choices as characterized in (23) and (24). The result then follows immediately from Proposition 1.

We now turn to part (2). The level of household production chosen by the naive couple in the first period, denoted $\bar{G}_{1}^{m}$, maximizes

$$
\begin{aligned}
V_{1} & =\sum_{i} \omega_{i}+2 \bar{G}_{1}^{m}-C\left(\bar{G}_{1}^{m}\right) \\
& +\beta \delta\left\{(1-F(\bar{\theta}))\left[\sum_{i}\left[\omega_{i}\left(1-\tilde{g}_{i 2}^{m}+\delta\right)\right]+(1+\delta) 2 \bar{G}_{2}^{m}\right]\right. \\
& \left.+2 \int_{\bar{\theta}}^{\infty} \theta f(\theta) \mathrm{d} \theta+F(\bar{\theta})\left[\sum_{i}\left[\omega_{i}\left(1-\tilde{g}_{i 2}^{d}+\delta\right)\right]+(1+\delta) \Lambda \bar{G}_{2}^{d}\right]\right\} .
\end{aligned}
$$

where $\bar{\theta}=\tilde{\theta}\left(\bar{G}_{1}^{m}\right)$ and $\bar{G}_{2}^{k}=\bar{G}_{1}^{m}+v\left(\tilde{g}_{s 2}^{m}, \tilde{g}_{h 2}^{m}\right)$ reflecting the couple's belief that they will behave efficiently at $t=2$ conditional on any first period choice $G_{1}^{m}$.

The first order condition satisfied by $\bar{G}_{1}^{m}$ can then be written as follows:

$$
\begin{aligned}
C^{\prime}\left(\bar{G}_{1}^{m}\right)= & 2+\beta \delta(1+\delta)[(1-F(\bar{\theta})) 2+F(\bar{\theta}) \Lambda] \\
& +\beta \delta f(\bar{\theta}) \tilde{\theta}^{\prime}\left(\bar{G}_{1}^{m}\right)\left\{-\left[\sum_{i} \omega_{i}\left(1-\tilde{g}_{i 2}^{m}+\delta\right)+(1+\delta) 2 \bar{G}_{2}^{m}\right]\right. \\
& \left.+\left[\sum_{i} \omega_{i}\left(1-\tilde{g}_{i 2}^{d}+\delta\right)+(1+\delta) \Lambda \bar{G}_{2}^{d}\right]-2 \bar{\theta}\right\} .
\end{aligned}
$$

Additionally substituting for $\bar{\theta}=\tilde{\theta}\left(\bar{G}_{1}^{m}\right)$ using the characterization in eq. (24) reveals that the terms in the large square brackets cancel out. The result then follows immediately from a comparison of

$$
C^{\prime}\left(\bar{G}_{1}^{m}\right)=2+\beta \delta(1+\delta)\left[2-(2-\Lambda) F\left(\tilde{\theta}\left(\bar{G}_{1}^{m}\right)\right)\right],
$$

with the first best characterization in (25) using convexity of the cost function.

Proof of Proposition 6. Note that that the condition that characterizes the first period investment level $\bar{G}_{1}^{m}$ by a naive couple can be written as in (A42) whereas the condition that characterizes the first period investment level $\hat{G}_{1}^{m}$ by a sophisticated 
couple can be written as in (A8). Since the cost function is the same, $\bar{G}_{1}^{m} \geq \hat{G}_{1}^{m}$ if and only if

$$
F\left(\tilde{\theta}\left(\bar{G}_{1}^{m}\right)\right) \leq F\left(\hat{\theta}\left(\hat{G}_{1}^{m}\right)\right)-\chi f\left(\hat{\theta}\left(\hat{G}_{1}^{m}\right)\right),
$$

where $\chi$ is defined as in (21). Then define

$$
\kappa \equiv \frac{\chi}{\hat{\theta}\left(\hat{G}_{1}^{m}\right)-\tilde{\theta}\left(\bar{G}_{1}^{m}\right)} .
$$

Defining also

$$
\check{\theta}\left(G_{1}^{m}\right) \equiv \hat{\mathcal{C}}_{2} / 2-(1+\delta)\left[\left(G_{1}^{m}+\hat{v}_{2}^{m}\right)-(\Lambda / 2)\left(G_{1}^{m}+\hat{v}_{2}^{d}\right)\right],
$$

which, in line with efficiency, uses only $\delta$ discounting, but is evaluated at the laissezfaire second period time inputs, it follows that

$$
\chi=\frac{(1+\beta \delta)}{(1+\delta)}\left[\hat{\theta}\left(\hat{G}_{1}^{m}\right)-\check{\theta}\left(\hat{G}_{1}^{m}\right)\right],
$$

whereby

$$
\kappa=\frac{(1+\beta \delta)}{1+\delta}\left[\frac{\hat{\theta}\left(\hat{G}_{1}^{m}\right)-\check{\theta}\left(\hat{G}_{1}^{m}\right)}{\hat{\theta}\left(\hat{G}_{1}^{m}\right)-\tilde{\theta}\left(\bar{G}_{1}^{m}\right)}\right] .
$$

But, $\check{\theta}\left(\hat{G}_{1}^{m}\right) \simeq \tilde{\theta}\left(\bar{G}_{1}^{m}\right)$ since both involve discounting by $\delta$ only. Hence $\bar{G}_{1}^{m} \geq \hat{G}_{1}^{m}$ if and only if

$$
\kappa\left[\hat{\theta}\left(\hat{G}_{1}^{m}\right)-\tilde{\theta}\left(\bar{G}_{1}^{m}\right)\right] f\left(\hat{\theta}\left(\hat{G}_{1}^{m}\right)\right) \leq F\left(\hat{\theta}\left(\hat{G}_{1}^{m}\right)\right)-F\left(\tilde{\theta}\left(\bar{G}_{1}^{m}\right)\right)
$$

with $\kappa \simeq(1+\beta \delta) /(1+\delta)$. 